\title{
Who receives specialist palliative care in Western Australia — and who misses out
}

Funded by

National Health and Medical Research Council

(NHMRC) 


\section{Copyright}

Readers are reminded that Australian Copyright laws automatically protect this report. No part of the report can be copied, cited or used in any way without permission from, and acknowledgement of, the authors. All rights reserved.

The authors are preparing to publish the findings of this study in peer-reviewed journals, ensuring that the material will be available in the public domain.

(C) 2004

For further information about this report please contact:

\author{
Dr Beverley McNamara \\ School of Social and Cultural Studies \\ The University of Western Australia \\ 35 Stirling Highway \\ CRAWLEY \\ Western Australia 6009 \\ Phone: +610893802742 \\ Fax: +61 0893801062 \\ Email: bevmc@cyllene.uwa.edu.au
}

\author{
Dr Lorna Rosenwax \\ Faculty of Medicine and Dentistry \\ The University of Western Australia \\ 35 Stirling Highway \\ CRAWLEY \\ Western Australia 6009 \\ Phone: +610893467245 \\ Fax: +61 0893462369 \\ Email: lornak@cyllene.uwa.edu.au
}

Printed by Uniprint 


\section{Principal Investigators}

Beverley McNamara, Senior Lecturer, School of Social and Cultural Studies, The University of Western Australia. BA(Hons) PhD

Lorna Rosenwax, Sub Dean (Health Science), Faculty of Medicine and Dentistry, The University of Western Australia. BAppSc(OT) PGradDipHlthSc MSc PhD

C. D'Arcy Holman, Professor, School of Population Health, The University of Western Australia. MBBS PhD

Ellen Nightingale, Formerly Director, Cancer Services Division, Cancer Foundation Centre for Palliative Care. RN MSc

\section{Associate Investigators}

Gill Lewin, Research Department Manager, Silver Chain Nursing Association. BSc(Hons) MPH MClinPsych PhD

Dimitris Matsakidis, Manager of the Aged Care Research and Evaluation Unit, School of Population Health, The University of Western Australia. BSc

\section{Research Staff}

Janine Calver, Research Fellow, School of Population Health, The University of Western Australia. BSc(Hons) PhD

Sheridan Howard, Research Associate, Faculty of Medicine and Dentistry, The University of Western Australia. BHlthSc(Hons)

Marie Blackmore, Research Officer, School of Social and Cultural Studies, The University of Western Australia. BSc(Hons) PhD

\section{Acknowledgements}

This research was funded and supported by the National Health and Medical Research Palliative Care Research Programme. We gratefully acknowledge the many people who contributed to this research, including Di Rosman and staff at the Western Australian Data Linkage Unit, The Department of Health, Western Australia; and Lyn Jones and Alison Atkins from The Silver Chain Nursing Association.

We are particularly grateful to the participants of the focus groups, which included palliative care professionals and volunteers as well as representatives from other Western Australian community health organisations. Overall the success of the project has been reliant on the support, encouragement and advice extended by the palliative care community of Perth. 


\section{Executive summary}

Our research describes the provision of palliative care services at a time of transition. Typically, palliative care has offered a holistic, non-curative focus with an emphasis on improving the quality of life of people with life-limiting conditions. Traditionally it has aimed to improve the conditions of people who were dying of cancer. Palliative care now seeks to extend a holistic, team-based and family-centred approach to people with other life-limiting conditions. Until now the degree to which this aim was reflected in the actual provision of health services has been unclear. There has been a paucity of population-based data on which to base equitable healthcare decision-making regarding the extension of palliative care to people suffering from a range of life-limiting, complex and painful conditions. Our study provides such data for Western Australia and provides an insight into who is missing out on palliative care services in the last year of life.

The study was a longitudinal, population-based, retrospective cohort study of 26,882 people who died in Western Australia between 1 July 2000 and 31 December 2002. A secondary analysis was conducted of data from the Silver Chain Nursing Association and two administrative health databases of the Western Australian Data Linkage System: the Mortality Register and the Hospital Morbidity Data System.

Three possible palliative care constituencies (that is, groups of people who would benefit from palliative care) were proposed in order to model three scenarios of service provision:

(a) a minimal constituency. That is, a disease-based potential palliative care constituency composed of people who died of any of the following 10 conditions: cancer, heart failure, chronic obstructive pulmonary disease, renal failure, Alzheimer's disease, liver failure, Parkinson's disease, motor neurone disease, HIV/AIDS, and Huntington's disease;

(b) a mid-range constituency. That is, a condition-based potential palliative care constituency composed of people who were hospitalised in the last 12 months of their lives for a condition listed as an underlying cause of death on their death certificate; and

(c) a maximal constituency. That is, a condition-based potential palliative care constituency composed of people who died from all causes except those that produced sudden deaths, defined as poisoning, injury, or originating during pregnancy or the puerperium.

\section{Key Findings 1}

The minimal constituency represented $50 \%$ of all deaths during the 2.5 -year study period, $54 \%$ of which were attributed on the death certificate to cancer. Four out of five of people in the minimal constituency were aged over 65 years; one in 50 was Aboriginal; half were married and a third were widowed; seven out of 10 lived in a major city; and a third were socioeconomically disadvantaged.

About half of the people in the minimal constituency died in hospital, about a third in their usual place of residence, the remainder in a residential aged care facility or elsewhere. Use of specialist palliative care services reduced the likelihood of dying in hospital or in a residential aged care facility.

\footnotetext{
${ }^{1}$ Only results from the minimal constituency are reported in the Executive Summary.
} 
The rate of use of specialist palliative care services by people dying of malignancies (68\%) was much higher than the rate for people dying of non-malignant conditions (8\%). In addition, people were less likely to receive specialist palliative care services if they were aged 84 years or over; female; Aboriginal; living in a remote area; or socioeconomically disadvantaged.

In the last 12 months of life, one person in four in the minimal constituency had a hospital admission for specialist palliative care services, whereas nine people out of 10 had a hospital admission not involving specialist palliative care services. Our findings suggest that the use of specialist palliative care services potentially reduces the demand on other hospital beds.

Slightly less than one person in three received home-based specialist palliative care services in the last 12 months of life. People who received home-based specialist palliative care services were more likely to receive home-based non-palliative services. People who received homebased non-palliative care services, and did not receive home-based specialist palliative care services, had more visits and more home hours of home-based non-palliative care services than people who received home-based specialist palliative care services and home-based nonpalliative care services.

People who received specialist palliative care services at home and/or in hospital spent more time in hospital than people who did not receive any specialist palliative care services. However, people who received only home-based specialist palliative care services spent less time in hospital than people who did not receive any specialist palliative care services. Referral to home-based palliative care therefore potentially ensures the best possible, and most appropriate use, of the various kinds of home-based services.

The annual cost of providing hospital-based specialist palliative care services in Western Australia for the study period was calculated at $\$ 9.2 \mathrm{M}$. If one half of all people in the minimal constituency had received hospital-based specialist palliative care services, this cost would have been doubled to $\$ 18 \mathrm{M}$. Providing home-based specialist palliative care services to one half of this constituency would cost $\$ 9.1 \mathrm{M}$, based on current home-based costs.

\section{Conclusions}

Our study identified those people who are the most disadvantaged in respect to receiving specialist palliative care services. A significant proportion of people within one of our potential palliative care constituencies, and who died in the period July 2000 to December 2002, did not receive specialist palliative care. These people may have received other forms of health care. They may also have benefited from the holistic, family-oriented services provided by generalist palliative care services. Not surprisingly, and given the traditional palliative care focus on cancer, those people dying of cancer were well serviced in comparison to people dying from other complex and painful conditions. Nevertheless one third of the people who died of cancer did not receive specialist palliative care.

Other measures of disadvantage have been noted that are reflective of broader disadvantage within Australian health care. To be Aboriginal, elderly, living in a rural or remote area and to be socially disadvantaged lessens one's chance of receiving appropriate, and apparently cost effective, services in the last weeks and months of life. By pointing to the areas of most critical need, this study assists policy and planning in the provision of health services.

Our study focuses on people who are not receiving specialist palliative care services, while also providing a unique window into Western Australian palliative care services. Once clients 
have been referred to palliative care, they are provided with a cohesive service by the network of local providers. Those who receive specialist palliative care services in hospital are more likely to receive home-based palliative care and the reverse is also true. This group of people are also more likely to die in their own homes, a common request of dying people that has been reported in the literature and anecdotally by health care providers.

By providing a comprehensive and empirically grounded picture of services used in the last year of life, this study has sought to develop and test a universally accepted normative benchmark for defining palliative care needs at population level. It makes a strong case for improving the range and level of palliative care provided to terminally ill people. Extending palliative care to accommodate even a minimal constituency is a costly exercise. Findings from our study allow informed advocacy to occur on behalf of vulnerable populations in a country that prides itself on universal access to high quality health services. 


\section{Contents}

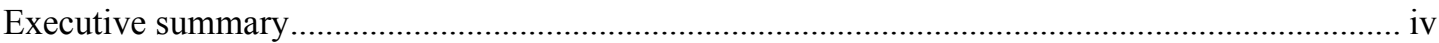

Key Findings ................................................................................................ iv

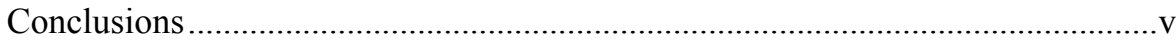

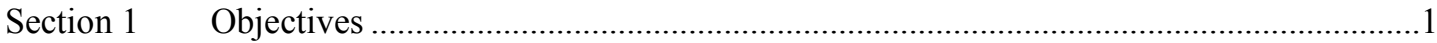

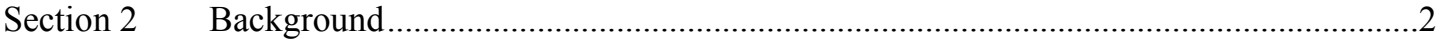

Palliative care constituencies: Who should receive palliative care? .......................2

Socio-demographic characteristics of people in the palliative care constituencies

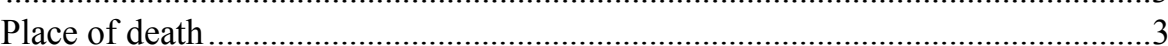

Palliative care patterns of delivery .............................................................. 4

Home- and hospital-based palliative care services ...............................................

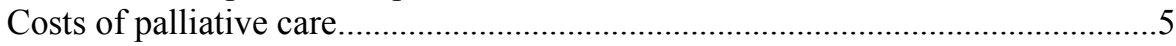

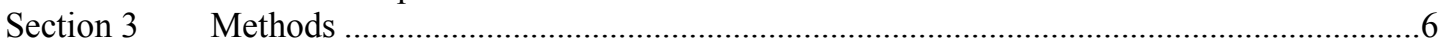

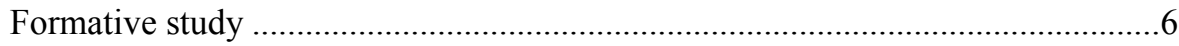

Longitudinal, population-based, retrospective cohort study ………......................6

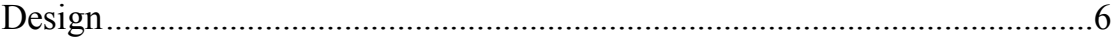

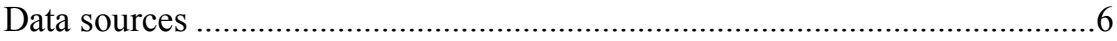

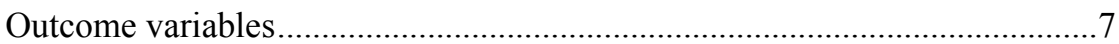

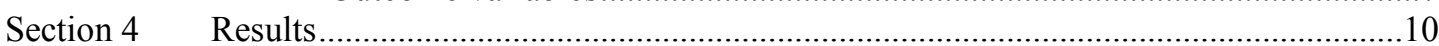

Defining a model of palliative care constituencies of potential need...................10

Perspectives from the formative study ...........................................................10

Defining a conceptual model of palliative care constituencies.......................11

Describing the Western Australian palliative care constituencies ........................13

The sizes of the three constituencies ..............................................................13

Proportions of the population with each condition in the minimal

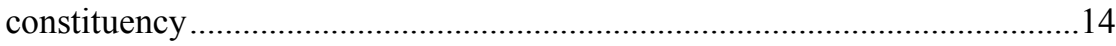

Demographic characteristics of people in the three palliative care

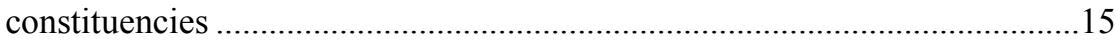

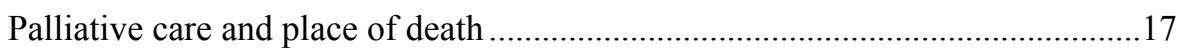

Place of death for people in the palliative care constituencies ......................17

Effects of receiving palliative care on place of death ....................................18

Specialist palliative care delivery patterns for population subgroups ...................19

Current levels of use of specialist palliative care services..............................19

Levels of use of specialist palliative care services for people with and

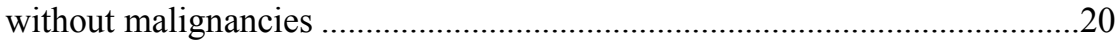

Levels of use of specialist palliative care services for socio-demographic

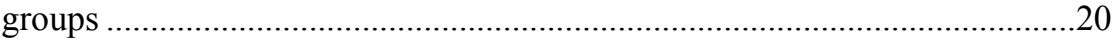

Home- and hospital-based specialist palliative care ............................................25

Hospital-based specialist palliative care services...........................................25

Home-based specialist palliative care services .............................................26

Specialist palliative care services and hospitalisations ……...........................27

A projected costing model for specialist palliative care ......................................28

Costing model for hospital-based specialist palliative care services .............28

Costing model for home-based specialist palliative care services..................29

Costing model for both hospital- and home-based specialist palliative care

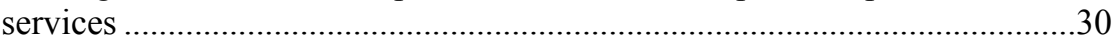

Section 5

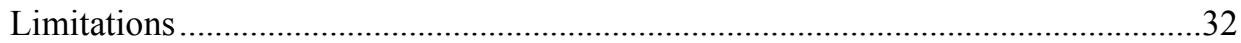

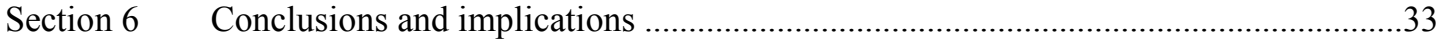

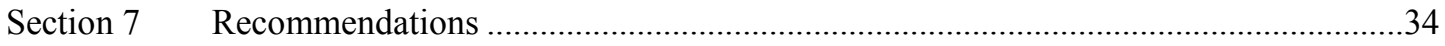

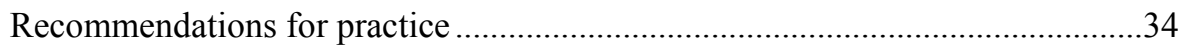

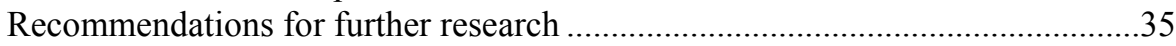

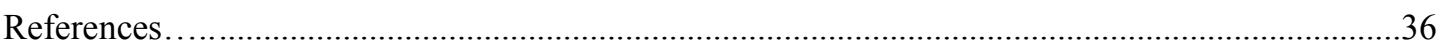




\section{Section 1 Objectives}

The objectives of the research were as follows:

1. To define who would benefit from receiving palliative care, that is, to define a model of palliative care constituencies.

2. To describe the characteristics of the people in Western Australian in the palliative care constituencies in terms of their condition, age group, gender, aboriginality, geographical remoteness and socioeconomic disadvantage.

3. To determine where people in the Western Australian palliative care constituencies die, and the effects of receiving palliative care during the last 12 months of life on their place of death.

4. To study patterns of delivery of specialist palliative care services during the last 12 months of life, comparing use between different socio-demographic groups and causes of death.

5. To study the relationships between home-based and hospital specialist palliative care services for people during the last 12 months of life.

6. To develop a model to estimate the cost of an increased demand on specialist palliative care services. 


\section{Section 2 Background}

Palliative care aims to improve the quality of life of people with life-limiting conditions by the emphasis on relief from pain and symptoms; by the involvement of their family and friends; and by the adoption of a holistic, non-curative focus. Historically, hospice and palliative care have focused on people with cancer, but have, more recently, extended to people with other conditions, such as neurodegenerative diseases, respiratory diseases, end stage organ failure and HIV/AIDS.

While a palliative care approach should be a vital and integral part of all clinical practice, whatever the illness or stage, specialist palliative care offers specific end-of-life services that are informed by knowledge and practice of palliative care principles and are supported by specialist palliative care services (SPCS). Such care is provided through a network of domiciliary care, day-care, hospital support and hospital- or hospice-based in-patient services.

In Australia there is limited evidence about the numbers of people who require access to SPCS. To address this need the following report provides a population-based study designed to estimate the proportion of people who are receiving SPCS and who should be receiving it during the last 12 months of life.

\section{Palliative care constituencies: Who should receive palliative care?}

Specialist palliative care has traditionally been provided to people with malignant conditions, and even now, the vast majority of people who receive SPCS have been diagnosed with cancer ${ }^{1}$. However, it is now widely acknowledged that the needs of many people dying of nonmalignant conditions are as great as the needs of those with malignant conditions. The holistic and family-based focus provided through SPCS could benefit these people $e^{2-4}$.

People with non-malignant conditions receive less SPCS than people with malignant conditions for various reasons including patterns of referral ${ }^{5-6}$; problems in estimating prognosis, especially end of life ${ }^{7-8}$; concerns of medical practitioners and other healthcare workers about their lack of palliative care skills ${ }^{9-11}$; and the differences in the needs of people with non-malignant conditions ${ }^{8,12}$.

Few studies define the extent of need for SPCS among the general population. One such study, conducted in South Australia ${ }^{13}$, estimated that $70 \%$ of people with life-limiting illnesses would benefit from SPCS. Another study of the general population, conducted in the United Kingdom ${ }^{3}$, compared the needs of people with malignant and non-malignant conditions by surveying their families. The researchers determined the average level of need in people with malignancies (in terms of number of symptoms, number of distressing symptoms, and number of symptoms lasting for more than six months). They investigated the same variables in people with non-malignant conditions and found that $17 \%$ of people who died from non-malignant conditions had needs that were at least as great as the average level of need in people with malignancies in terms of these three criteria. They estimated that providing SPCS for these people would represent a $79 \%$ increase in the need for SPCS. They add, however, that this is only a conservative estimate of need because it selects people with non-malignant conditions with a level of severity comparable to that of the one third of people with the most advanced malignant conditions. 
The calls to extend SPCS to non-malignant populations and the paucity of research in this area, led to the first objective in the present study. This first objective was to define who would benefit from receiving palliative care, that is, to define a model of palliative care constituencies.

\section{Socio-demographic characteristics of people in the palliative care constituencies}

Palliative Care Australia has stated in its strategic plan of 2003-2006 that its vision is to provide the 'world's best palliative care for ALL Australians'. To accomplish this vision, its first strategic aim is to 'improve equity and access to palliative care across Australia', partly by means of 'identify[ing] gaps and inequities in service provision and research and advocat[ing] for solutions'. The present study helps to address this aim by providing population data about the socio-demographic characteristics of people requiring palliative care in Western Australia.

Defining and describing the palliative care constituency in Western Australia is useful for healthcare planning from several points of view:

1. It provides data about the numbers of people who may require SPCS, thus facilitating planning of the extent of the services.

2. It provides data about the characteristics of people who may require SPCS, thus facilitating planning of the nature and distribution of services in terms of:

- conditions requiring services;

- ages and gender distribution of people requiring services;

- proportions of Aboriginal people requiring services;

- geographical distribution of people requiring services; and

- socioeconomic levels of people requiring services.

The second objective of the present study, therefore, was to describe the characteristics of the people in Western Australia in the palliative care constituencies in terms of their condition, age group, gender, aboriginality, geographical remoteness and socioeconomic disadvantage.

\section{Place of death}

One of the goals of SPCS is to enable people to die in the way that they wish. Most people, when asked where they wish to die, express a wish to die at home ${ }^{14-16}$. Place of death, however, is correlated with a variety of factors outside the patient's control, including the condition causing death ${ }^{17,18}$; the patient's age ${ }^{17,19-24}$; socioeconomic level ${ }^{23,25-26}$; level of family support $^{15,20,22}$; gender ${ }^{17,20-21,24}$; whether the patient is single ${ }^{20-21}$; and the period of time between diagnosis and death ${ }^{24}$. SPCS can also influence place of death. In general, people who receive SPCS are more likely to die at home $e^{27-29}$ and also more likely to die where they wish ${ }^{15}$.

The third objective of the present study, therefore, was to determine where people in the Western Australian palliative care constituencies die, and the effects of receiving palliative care during the last 12 months of life on their place of death. 


\section{Palliative care patterns of delivery}

Previous studies show that people with cancer access SPCS more than people with other conditions. One study of four palliative care services in London reported that $95 \%$ of the patients had been diagnosed with cancer ${ }^{1}$. A South Australian survey of bereaved families and friends in the general population reported that palliative care services had been accessed in $61 \%$ of cases when the decedent had had cancer, but in only $36 \%$ when the decedent did not have cancer ${ }^{13}$. A population-based, South Australian study confirmed that most people who die of cancer $(68 \%$ in 1999$)$ receive $\mathrm{SPCS}^{30}$.

The socio-demographic characteristics of people receiving SPCS are less well known. A South Australian, population-based study determined the socio-demographic characteristics of people with cancer who received SPCS ${ }^{30}$. In this study, people were less likely to receive services if they were 80 years and over; came from a rural area; and had three months or less between diagnosis and death. Gender, socioeconomic status and race, however, did not predict whether a person received SPCS. Other research also shows that people over 80 years are less likely to receive SPCS ${ }^{31}$. This information is restricted to people with cancer. Until now there has been no similar Australian population-based data on people who die of other conditions.

Objective four of the present study was to study patterns of SPCS delivery during the last 12 months of life comparing use between different socio-demographic groups and conditions causing death

\section{Home- and hospital-based palliative care services}

People with life-limiting conditions and their families usually prefer the patient to remain at home for as much of the time as possible and to die at home if that can be achieved in comfort and security ${ }^{14-16,32-33}$. Home-based SPCS, therefore, have been established to meet patients' and families' needs as much as possible in the home environment. Early work in this area found that patient pain and carer anxiety were increased when care was provided in the home ${ }^{34}$. However, pain control in SPCS, both at home and in hospices, has improved greatly over the past few years and is now very effective ${ }^{35}$.

Hospital admissions occur during the closing stages of life for several reasons. One reason is the deterioration of the patient's health to a point where it cannot be adequately treated at home $\mathrm{s}^{36,37}$. Another factor that leads to hospital admissions is the inability of carers to maintain an adequate level of care owing to the physical, psychological and/or financial stress of caregiving over an extended time period ${ }^{37,38}$. A third factor is insufficient coordination of or support by healthcare services to maintain home care ${ }^{36,37}$.

Hospital admissions frequently occur for reasons unrelated to the condition causing death. In a study of 41 deaths in a retirement community occurring over an 18 -month period, $46 \%$ of people had been admitted to hospital in the last year of life, and these hospital admissions were for acute conditions, such a pneumonia (52\%), and accidental injuries (15\%) as well as for endstage chronic diseases $(33 \%)^{39}$.

Few studies report the numbers of people in the population who receive home-based SPCS, hospital-based SPCS or a combination of the two. The present study reports these figures for 
the Western Australian population. Objective five was to study the relationships between home-based and hospital SPCS for people during the last 12 months of life.

\section{Costs of palliative care}

End-of-life care is costly. In one study, the cost of caring for old people in their last year of life was $276 \%$ higher than the cost of caring for age-matched old people who were not in their last year $^{40}$.

Australia is faced with the challenge of a finite specialist palliative care budget and mounting pressure to expend these services to all people dying from advanced incurable diseases. This challenge is amplified by the lack of reliable and representative data about the needs of dying people. This information is crucial, especially in the context of current health funding. In Western Australia, palliative care receives about $0.5 \%$ of the $\$ 2.6$ billion allocated by the State Government to health. Palliative care professionals have raised concern about this situation ${ }^{41}$, suggesting: (a) that patients are missing out on specialised pain relief and psychological support; (b) that directing money into intensive care beds as opposed to palliative care beds is a poor use of resources; and (c) that the non-promotion of palliative care services is due to their scarceness. The Director General of the Western Australian Health Department has said that more research and planning are needed to determine future demand for palliative care services. This includes investigating who is missing out and why this is the case ${ }^{41}$.

Specialist palliative care services may reduce costs. Recently, Marie Curie Cancer Care in the United Kingdom stated that that $£ 100 \mathrm{M}$ in hospital beds could be saved each year by providing home care for 37,000 patients $^{42}$. There is evidence that specialist palliative care services, particularly when delivered at home, reduce $\operatorname{costs}^{43-46}$, though this may vary, for instance when the period of service provision is extended ${ }^{43,47}$. However, randomized controlled trials comparing different specialist palliative care services with one another and with conventional care are fraught with methodological difficulties ${ }^{37,48-49}$, and further well-controlled studies are still needed in this area $^{50}$.

At the same time, information concerning the current costs of specialist palliative care provision, as well as the projected costs of providing these services to people with nonmalignant conditions, is essential for policy and planning. The present study provided an opportunity to obtain such data. Objective six, therefore, was to develop a model to estimate the cost of an increased demand on SPCS. 


\section{Section 3 Methods}

Two studies were conducted: A formative study was conducted to obtain the perspectives of palliative care stakeholders and a population-based, retrospective cohort study was conducted to obtain a description of the people in Western Australia who are currently receiving specialist palliative care services (SPCS) and the people who would be likely to benefit from SPCS. The results of the formative study informed Objective one. The results of the population-based study informed Objectives two to six.

\section{Formative study}

Written invitations to participate in the study were sent to facilities that provided palliative care and care for aged people, special interest groups and individuals known to be working in the area in Western Australia. Participants included volunteer carers, as well as staff from palliative care sites, acute care hospitals with palliative care units, domiciliary nursing services and aged care facilities. Both private and public hospitals, and both city and rural settings, were represented. Professionals included social workers, nurses, medical practitioners, occupational therapists and physiotherapists. Six focus groups, composed of 38 participants, were conducted. Four other participants, who were unable to attend the focus groups, were interviewed individually.

The groups were facilitated by the first two principal investigators. Four guiding questions were used with the focus groups: (a) What is palliative care? (b) Who should receive palliative care? (c) At what point in the illness history should palliative care be offered? and (d) What diagnostic categories of illness should receive palliative care? Focus groups were conducted around these four questions until saturation (repetition of the same themes by different participants with no new themes) occurred ${ }^{51}$.

Common themes were generated from the discussion in the focus groups and the interviews.

\section{Longitudinal, population-based, retrospective cohort study}

\section{Design}

The main study was a longitudinal, population-based, retrospective cohort study of the people who died in Western Australia from 1 July 2000 to 31 December 2002. The cohort was defined over a 2.5 -year period to coincide with ICD-10-AM $\operatorname{codes}^{52}$.

\section{Data sources}

This study relied on the secondary analysis of data from the Silver Chain Nursing Association and two administrative health databases of the Western Australian Data Linkage System (WADLS): the Mortality Register and the Hospital Morbidity Data System.

The Western Australian Record Linkage system (shown in Figure 1) links together data from over a period of 20 years, and from a variety of administrative data sets, and relates these to individual people ${ }^{53}$. The system consists of six core datasets: birth records, midwives' notifications, cancer registrations, inpatient hospital morbidity data, inpatient and public outpatient mental health services data and death records. Residential and community care data 
sets, as well as pharmaceutical and medical benefits records, are being added to the system as they become available ${ }^{53}$. The WA Record Linkage Project has been validated for a similar study that focused on patterns of care and the outcomes of health services for end-stage renal disease $\mathrm{s}^{54}$. There are three main advantages of using data from the record linkage project. First, it is more cost-effective than studies that rely on primary data collection and data entry. Second, it avoids problems that result when individuals are lost to follow-up or do not respond. Last, the privacy of the medical records is fully protected, because probabilistic matching techniques are used for the linkages between health data sets ${ }^{54}$.

The Silver Chain Nursing Association database provided information regarding home-based SPCS during the last 12 months of life. Silver Chain provides over $90 \%$ of the home-based SPCS in Western Australia.

The Mortality Register contained information from death certificates. The death certificate is completed by a doctor or coroner and describes the cause of death. It consists of two parts. Part 1 of the Death Certificate lists the sequence of diseases or conditions that led directly to death (the 'morbid train of events'). The last recorded cause in Part 1 of the Death Certificate is called the 'Underlying Cause of Death'. Part 2 of the Death Certificate records other diseases or conditions that contributed to the death but were not directly attributable to the morbid train of events that led to death. This study used data from Part 1 only of the Death Certificate.

The Hospital Morbidity Data System provided information regarding hospital-based SPCS during the last 12 months of life. Specialist palliative care admissions were identified from the Type of Episode of Care data item.

\section{Figure 1: The Western Australian Data Linkage System}

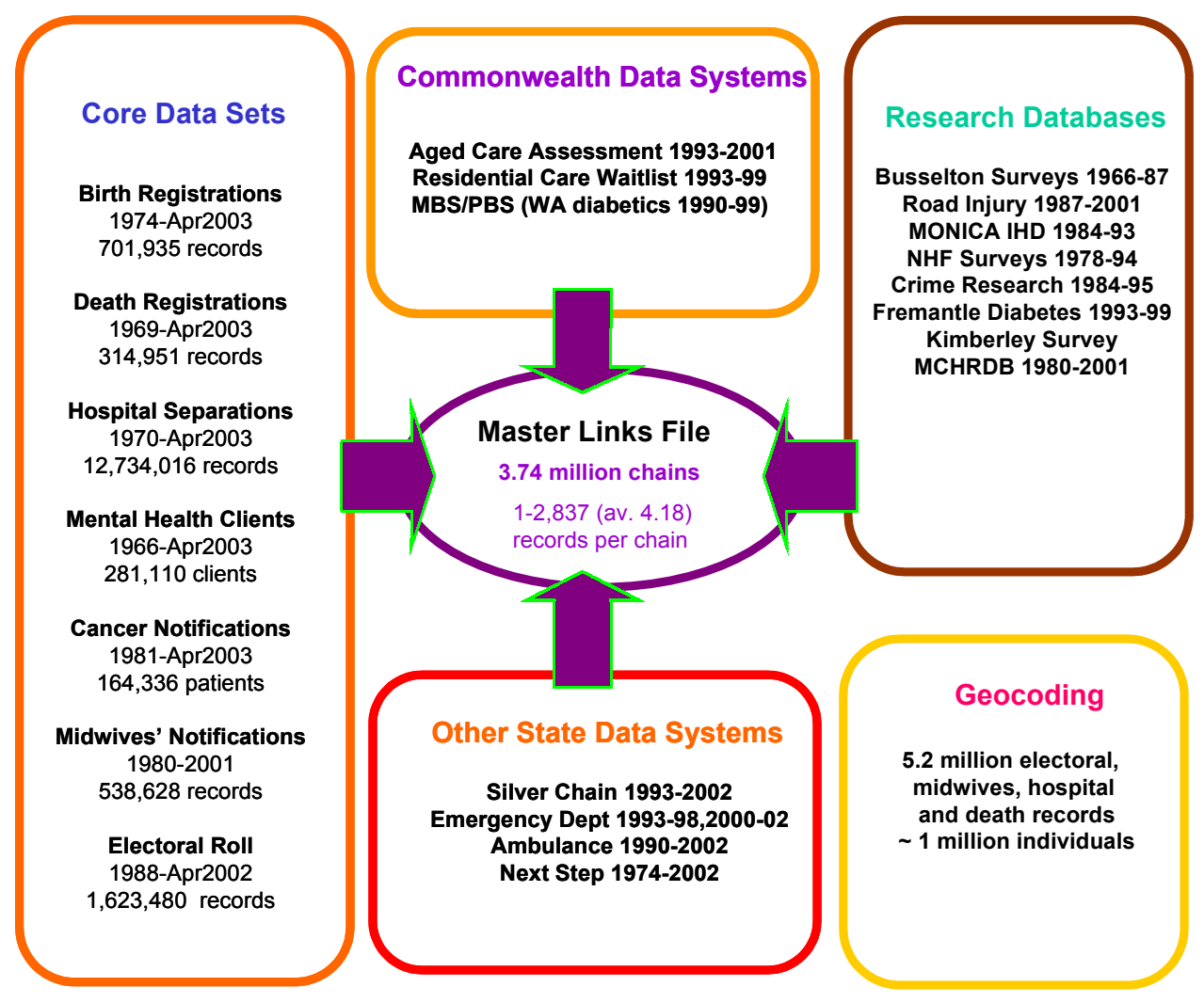




\section{Outcome variables}

The outcome variables in this study were as follows:

1. Cause of death

2. Place of death

3. Use of SPCS in the last 12 months of life

4. Demographic variables

For the purposes of analysis, cause of death was coded as malignant (ICD 10 codes: C00 D48) or non-malignant. Nine non-malignant causes of death were given particular attention. These were:

- $\quad$ heart failure (ICD 10 codes: I500, I501, I509, I111, I130, I132);

- $\quad$ renal failure (ICD10 codes: N180, N188, N189, N102, N112, N132, N120, N131, N132; but excluding acute renal failure: ICD10 code N17);

- $\quad$ chronic obstructive pulmonary disease (ICD10 codes: J40, J410, J411, J418, J42, J430, J431, J432, J438, J439, J440, J441, J448, J449);

- $\quad$ Alzheimer's disease (ICD10 codes: G300, G301, G308, G309);

- $\quad$ liver failure (ICD10 codes: K704, K711, K721, K729);

- $\quad$ Parkinson's disease (ICD10 code: G20);

- $\quad$ Motor Neurone Disease (ICD10 code: G122);

- HIV/AIDS (ICD10 codes: B20 - B24); and

- Huntington's disease (ICD10 code: G10).

Place of death was coded in terms of location and accommodation setting. Location was coded as the usual place of residence or elsewhere. Accommodation setting was coded as hospital, hospice, aged-care facility or other. 'Other' accommodation included private residences (owned or private/public rental), independent living units within retirement villages, boarding houses, supported accommodation facilities other than residential aged care facilities, and temporary shelters.

To determine whether receiving palliative care during the last 12 months of life affected where people died, multinomial logistic regression was used. This analysis was performed on the minimal constituency, which consisted of 11,752 people after excluding those who died in a hospice, were aged less than 35 years, or had missing SEIFA or ARIA values. Deaths in a hospice were excluded as an outcome variable because it is a specialist palliative care service and, therefore, could not be used as both an independent and dependent variable. People aged less than 35 years were excluded from the analysis because the validity of the multinomial logistic regression model was compromised by the age variable containing categories with no count data (i.e., no people aged less than 35 years died in a residential aged care facility). The analysis was adjusted for the following known confounders: age, gender, aboriginality, social disadvantage, geographic remoteness, place of residence prior to death, and cause of death (i.e., the 10 tracer conditions that defined the minimal estimate).

Use of SPCS in the last 12 months of life was divided into hospital-based SPCS and homebased SPCS. Individuals could be receiving both, one or neither. Hospital-based SPCS was described in terms of: (a) its presence or absence, (b) the number of admissions, and (c) the 
length of stay for each admission. Home-based SPCS was described in terms of: (a) its presence or absence, (b) the number of visits and (c) in-home client attributable time (hours) for each visit.

The demographic variables recorded in this study were as follows:

- $\quad$ Age, derived from the Mortality Register, and grouped into 10-year age groups, with a 1-14 years age group and an $85+$ age group.

- Gender, derived from the Mortality Register.

- Aboriginality, derived from the Mortality Register and Hospital Morbidity Data System, coded as Aboriginal or not.

- Geographical remoteness, derived from the Accessibility Remoteness Index of Australia (ARIA+), and coded into six categories (major cities of Australia, inner regional Australia, outer regional Australia, remote Australia, very remote Australia, and migratory).

- Socio-economic disadvantage, derived from the Index of Socio-Economic Disadvantage (IRSD) taken from the Socio-Economic Indices for Areas, based on the 2001 Census (SEIFA). This was divided into five categories (most disadvantaged [lowest 10\%], more disadvantaged [next 15\%], average [next 25\%], less disadvantaged [next 25\%], and least disadvantaged [top 25\%]). 


\section{Section 4 Results}

\section{Defining a model of palliative care constituencies of potential need}

Key points

1. A conceptual model of palliative care constituencies (people likely to benefit from palliative care) was developed from the research literature and from focus groups and interviews with workers in the field. It consisted of minimal, mid-range and maximal constituencies.

2. The minimal palliative care constituency included people who died of any of the following 10 tracer conditions: cancer, heart failure, renal failure, chronic obstructive pulmonary disease, Alzheimer's disease, liver failure, Parkinson's disease, motor neurone disease, HIV/AIDS and Huntington's disease.

3. The mid-range palliative care constituency included people who were hospitalised in the last 12 months of life for a condition that was later listed as an underlying cause of death on their death certificate.

4. The maximal palliative care constituency included people who died from all causes except those that produced sudden deaths, defined as poisoning, injury, or originating during pregnancy or the puerperium.

Objective one was to define who would benefit from receiving palliative care, that is, to define a model of palliative care constituencies. A formative study was conducted to obtain perspectives of palliative care workers on this question. The results of this study as well as a literature review were used to construct a model of palliative care constituencies.

\section{Perspectives from the formative study}

As described in the Methods, the participants in the formative study were asked four questions: (a) What is palliative care? (b) Who should receive palliative care? (c) At what point in the illness history should palliative care be offered? and (d) What diagnostic categories of illness should receive palliative care?

With regard to the question of what palliative care is, there was a high level of agreement among participants in the focus groups and interviews on the essential components of palliative care. Common themes were: that palliative care is patient-centred; that it incorporates physical, psychological and spiritual nurturing; that it may be given alone or in conjunction with active treatment; that it is care that palliates; and that it is care that ensures quality of life until death. Notably, at this stage of the questioning, there was no suggestion that palliative care should be restricted to, or extended from, people dying of cancer.

With regard to the second question, who should receive palliative care, some participants expressed concern that this definition of palliative care was idealistic and not often achieved, and that, in reality, the kinds of care offered to dying people depend upon:

- funding models that allocate funding to medical care rather than people care;

- $\quad$ historical patterns of service delivery that target only people with cancer; 
- the lack of appropriate knowledge and skills for dealing with non-malignant end-stage conditions among healthcare workers;

- a lack of knowledge in the general population, leaving families of patients who might benefit from palliative care uninformed of the services that might benefit them;

- lack of coordination of services and territorial tensions between designated palliative care services and non-designated services that also care for people with end-stage conditions; and

- reluctance of doctors to refer their patients to palliative care because of the perception that doing so is an admission of failure.

These findings suggested that the focus upon cancer in palliative care was principally a function of organisational and cultural restraints, rather than because people with cancer were considered to have a greater need than those with other kinds of conditions.

When asked the third question, at what point in the illness history palliative care should be offered, participants agreed on the importance of offering palliative care early, possibly at the time of diagnosis, and ensuring its availability on request throughout the course of the illness. Participants also highlighted the need for palliative care at certain other points in the progress of patients' conditions, including the point when active treatment ceases, when a carer needs a respite, when there is need for symptom control, when the patient has a symptom that cannot be dealt with better elsewhere, and when the patient is dying (though it was acknowledged that the end stage of conditions with complex symptomatology was not always easy to pinpoint). These findings confirmed the need for a flexible approach to the development of a palliative care constituency.

As for the fourth question, concerning the diagnostic categories in which people should be given access to palliative care: apart from cancer, particular concern was expressed for people suffering from haematological and renal diseases; neurological disorders such as motor neurone disease; respiratory diseases such as cystic fibrosis; Alzheimer's disease; and cardiac conditions.

When asked to define a palliative care constituency, with particular attention as to how this may be limited in a practical sense, participants suggested the use of symptom- or needs-based as well as condition-specific considerations. Needs-based considerations include the extent to which the condition is life-limiting, the severity of the symptoms, the treatment options available, the kinds of support needed, and the choice of the patient and family.

\section{Defining a conceptual model of palliative care constituencies}

The findings from the focus groups confirmed that palliative care should be available to all who need it. They illustrated that palliative care services had focused on people with cancer, possibly to the neglect of those suffering from other life-limiting, complex and painful conditions. However, they also highlighted the need for a flexible and, possibly, a needs-based approach.

The challenges for the researchers in developing a model of palliative care constituencies were to take into account the methodological restrictions of population based research, while simulating, if possible, a potential needs-based approach. Using the feedback from the focus groups as a starting point, a review of the research literature was undertaken to identify the 10 conditions that most require palliative care. The 10 conditions that finally emerged within the 
literature and that confirmed findings from the focus groups were: cancer, heart failure ${ }^{12,55}$, renal failure ${ }^{56}$, chronic obstructive pulmonary disease ${ }^{55,57}$, Alzheimer's disease ${ }^{58-59}$, liver failure $^{60}$, Parkinson's disease ${ }^{61-62}$, motor neurone disease ${ }^{55,63}$, HIV/AIDS ${ }^{64}$ and Huntington's disease $^{65}$. These 10 conditions comprised a proposed minimal palliative care constituency. In other words, it was proposed that people diagnosed with any of these 10 conditions should be automatically eligible for specialist palliative care services (SPCS). While not all people suffering from these conditions may require or choose palliative care, it was also recognised that this is a conservative estimate of the people who might require palliative care. It is the most restrictive of the three potential needs-based constituencies proposed. Put another way, not all people within these 10 groups may require palliative care in the last year of their lives, but a large number will, and possibly others will that do not have one of the 10 listed conditions.

A second estimate, the mid-range palliative care constituency, was proposed to include people who were hospitalised during the 12-month period before their death, the reason for admission matching the underlying cause of death on the death certificate. These additional criteria signalled that the patient and doctors had some advance evidence that the patient's state of health was compromised, and that the disease did not arise immediately prior to death. While 12 months is an arbitrary period, palliative care services are often accessed during this time period. However, the mid-range could be defined variously by changing the time to reflect a level or urgency of potential need.

The third and most comprehensive estimate, the maximal palliative care constituency, included all but sudden deaths. It was defined so as to exclude poisoning, injury, or death originating during pregnancy, childbirth, the puerperium or the perinatal period. It was indicative of inclusive criteria of potential need, where palliative care could be appropriate for a wide range of dying people.

The definitions of the three palliative care constituencies are summarised in Table 1 .

Table 1: Definitions of the minimal, mid-range and maximal palliative care constituencies

\begin{tabular}{|c|c|c|}
\hline Estimate & Operational definition & Identification of cases \\
\hline Minimal & $\begin{array}{l}\text { Death from } 10 \text { causes: cancer, heart failure, renal failure, } \\
\text { liver failure, chronic obstructive pulmonary disease, } \\
\text { motor neurone disease, Parkinson's disease, Huntington's } \\
\text { disease, Alzheimer's disease and HIV/AIDS. }\end{array}$ & $\begin{array}{l}\text { Mention of any of the } 10 \text { causes in Part } \\
1 \text { of Death Certificate. }\end{array}$ \\
\hline $\begin{array}{l}\text { Mid- } \\
\text { range }\end{array}$ & $\begin{array}{l}\text { Person was admitted to hospital in the last } 12 \text { months of } \\
\text { life for the same condition recorded on the Death } \\
\text { Certificate. }\end{array}$ & $\begin{array}{l}\text { Underlying cause of death recorded on } \\
\text { the Death Certificate matched the } \\
\text { principal or secondary diagnosis fields } \\
\text { of the HMDS for admissions in the last } \\
\text { year of life. }\end{array}$ \\
\hline Maximal & $\begin{array}{l}\text { Deaths from all causes except: } \\
\text { - during pregnancy, childbirth or the puerperium (O00- } \\
\text { O99) } \\
\text { - } \text { originating during the perinatal period (P00-P96) } \\
\text { - resulting from injury, poisoning \& certain other } \\
\text { external causes (S00-T98); or } \\
\text { - resulting from external causes of morbidity and } \\
\text { mortality (V01-Y98) }\end{array}$ & $\begin{array}{l}\text { All deaths except those that mentioned } \\
\text { the excluded conditions in Part } 1 \text { of the } \\
\text { Death Certificate. }\end{array}$ \\
\hline
\end{tabular}




\section{Describing the Western Australian palliative care constituencies}

\section{Key points}

1. The minimal palliative care constituency included $50 \%$ of the population of people who died in Western Australia between 1 July 2000 and 31 December 2002. The mid-range palliative care constituency included $56 \%$ of this population, and the maximal palliative care constituency included $89 \%$.

2. Slightly more than half (54\%) of the minimal constituency died of malignancies, the most common remaining conditions being heart failure $(19 \%)$, renal failure $(9 \%)$, chronic obstructive pulmonary disease $(9 \%)$, Alzheimer's disease $(4 \%)$ and liver failure (3\%).

3. Of the people in the minimal constituency, four out of five were aged over 65 years; one in 50 was Aboriginal; half were married and a third were widowed; seven out of 10 lived in a major city; and a third were socioeconomically disadvantaged.

Objective two was to describe the characteristics of the Western Australian palliative care constituencies in terms of their condition, age group, gender, aboriginality, geographical remoteness, and level of socioeconomic disadvantage. This chapter uses the data from the population-based study to answer the objective:

- first, by indicating how many people, and thus what proportions of the population, are included in the three palliative care constituencies defined in the last chapter,

- $\quad$ second, by determining the proportions of people with each of the 10 tracer conditions included in the minimal palliative care constituency, and

- last, by describing the proportions of people in each constituency in terms of the demographic variables: age, gender, aboriginality, geographical remoteness, and level of socioeconomic disadvantage.

\section{The sizes of the three constituencies}

There were 27,971 deaths from all causes in Western Australia over the study period. Foetal deaths (i.e., deaths in utero) and deaths at less than 1 day of age $(n=509)$ were excluded, leaving 27,462 deaths. The underlying cause of death was missing in 580 records $(2.1 \%)$. Exclusion of these 580 records reduced the valid population to 26,882 . This population was used in all subsequent analyses.

The minimal palliative care constituency consisted of 13,453 people ( $50.0 \%$ of all deaths), or 283.2 deaths per 100,000 of the population per year.

The mid-range palliative care constituency consisted of 14,919 people ( $55.5 \%$ of all deaths) or 314.1 deaths per 100,000 of the population per year.

The maximal palliative care constituency consisted of 24,032 people ( $89.4 \%$ of all deaths), or 505.9 deaths per 100,000 of the population per year.

A diagrammatic representation of the palliative care constituencies model is shown in Figure 2. 


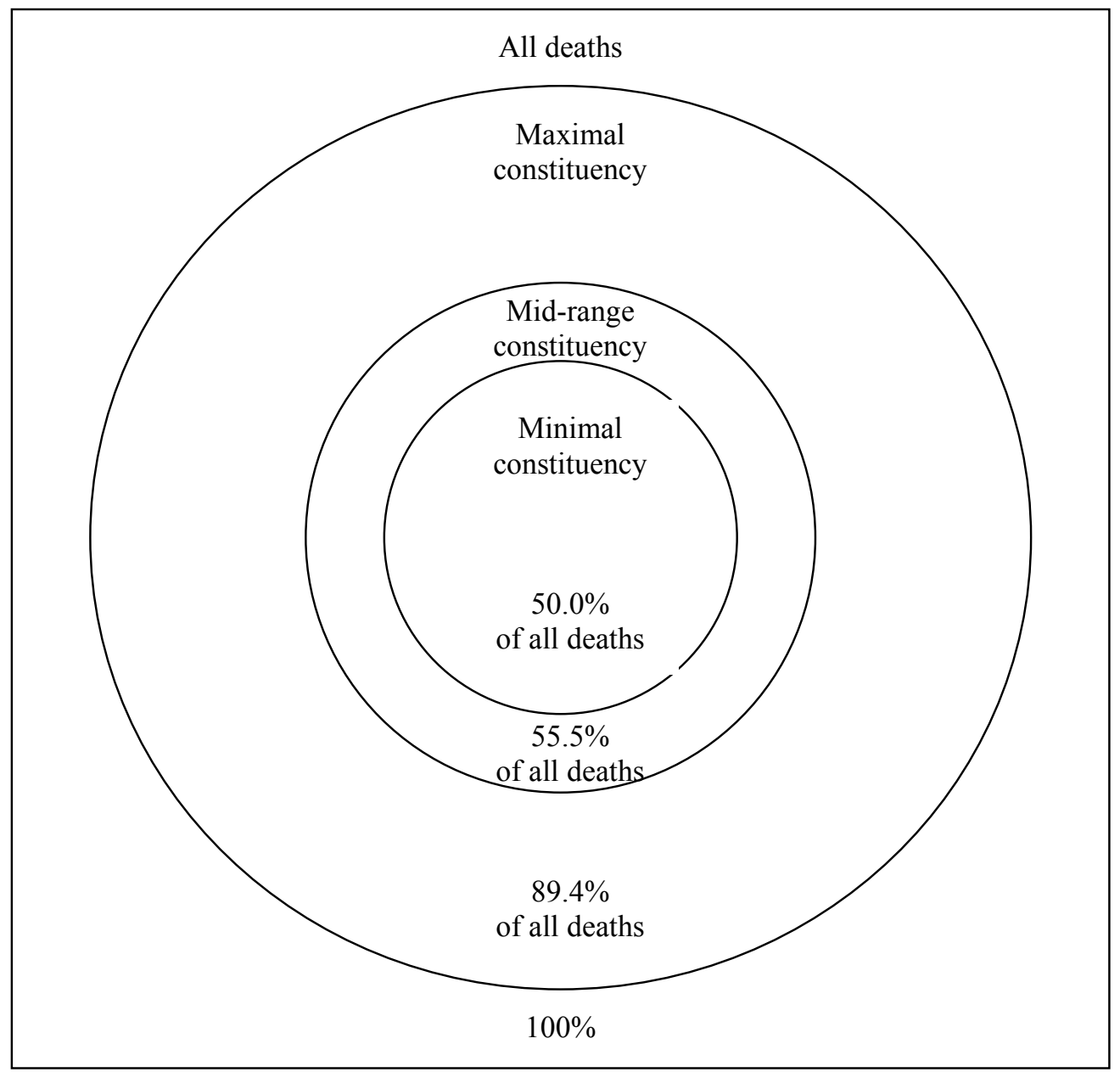

\section{Proportions of the population with each condition in the minimal constituency}

The minimal palliative care constituency was defined in terms of the presence of any of 10 tracer conditions as a cause of death. The percentages of deaths from each of the 10 tracer conditions within this constituency is shown in Table 2. Slightly over half of the people in this constituency died of a malignant neoplasm. The commonest non-malignant conditions were heart failure, renal failure, chronic obstructive pulmonary disease, Alzheimer's disease and liver failure.

The majority (91.3\%) of people in the minimal palliative care constituency died from one tracer condition, as shown in Table 3, but small proportions of the population had up to four conditions. 
Table 2: Frequency of 10 tracer conditions, Western Australia deaths from 1 July 2000 to 31 December $2002(n=14,709)^{1}$

\begin{tabular}{lr}
\hline Condition listed as a cause of death in death certificate & $\mathbf{\%}$ \\
\hline Neoplasm & 54.4 \\
Heart failure & 19.2 \\
Renal failure & 8.9 \\
Chronic Obstructive Pulmonary Disease & 8.7 \\
Alzheimer's disease & 3.6 \\
Liver failure & 2.9 \\
Parkinson's disease & 0.1 \\
Motor neurone disease & 0.1 \\
HIV/AIDS & $<0.1$ \\
Huntington's disease & $<0.1$ \\
\hline
\end{tabular}

It was impossible to distinguish between acute liver failure and chronic liver failure due to the nature of the ICD-10-AM coding system. Therefore, it is possible that some people who died from acute liver failure should have been excluded from the minimal estimate because the onset of disease and death was too rapid for them to benefit from specialist palliative care services.

Table 3: Proportions of people with one or more tracer conditions mentioned in Part 1 of the Death Certificate in the minimal palliative care constituency from 1 July 2000 to 31 December $2002(n=13,453)$

\begin{tabular}{cr}
\hline Number of tracer conditions & $\mathbf{\%}$ \\
\hline 1 & 91.3 \\
2 & 8.2 \\
3 & 0.6 \\
4 & $<0.1$ \\
\hline Total & 100.0 \\
\hline
\end{tabular}

Demographic characteristics of people in the three palliative care constituencies

As shown in Table 4, the people who comprised the palliative care constituencies (minimal, mid-range and maximal) tended to be:

- $\quad$ aged 65 years and older $(79 \%-82 \%)$;

- $\quad$ non-aboriginal (93\% - 94\%);

- $\quad$ married (43\% - 49\%) or widowed (33\% - 38\%);

- living in the major cities of Western Australian (71\% - 72\%); and

- socioeconomically advantaged (52\%), with one third being socioeconomically disadvantaged.

\footnotetext{
${ }^{1}$ Where a person died of more than one tracer condition (see Table 3), all conditions are listed. Consequently, in Table 2, N=14,709 (not 13,453, which is the size of the minimal constituency).
} 
Table 4: Demographic characteristics of the Western Australian palliative care constituency, July 2000 to December 2002

\begin{tabular}{|c|c|c|c|c|c|}
\hline \multicolumn{2}{|l|}{ Variable } & $\begin{array}{r}\text { Minimal } \\
(\mathrm{n}=\mathbf{1 3 , 4 5 3 )} \\
\%\end{array}$ & $\begin{array}{r}\text { Mid-range } \\
(\mathrm{n}=14,919) \\
\%\end{array}$ & $\begin{array}{r}\text { Maximal } \\
(\mathrm{n}=\mathbf{2 4 , 0 3 2 )} \\
\%\end{array}$ & $\begin{array}{l}\text { Total deaths } \\
(\mathrm{n}=\mathbf{2 6 , 8 8 2})\end{array}$ \\
\hline \multirow{11}{*}{ Age } & & & & & \\
\hline & LVIISsillg & 1 & & 2 & 3 \\
\hline & - 0 to 14 & 0.3 & 0.4 & 0.8 & 1.3 \\
\hline & - 15 to 24 & 0.3 & 0.3 & 0.3 & 1.5 \\
\hline & - 25 to 34 & 0.7 & 0.8 & 0.8 & 2.3 \\
\hline & - 35 to 44 & 2.0 & 2.0 & 2.1 & 3.1 \\
\hline & - 45 to 54 & 6.0 & 5.8 & 5.1 & 5.6 \\
\hline & - 55 to 64 & 11.9 & 11.2 & 9.4 & 9.2 \\
\hline & - 65 to 74 & 22.5 & 21.8 & 18.9 & 17.8 \\
\hline & - 75 to 84 & 31.7 & 32.1 & 31.5 & 29.8 \\
\hline & . $85+$ & 24.6 & 25.7 & 31.2 & 29.4 \\
\hline \multirow[t]{2}{*}{ Gender } & - Missing & 1 & 1 & 1 & 1 \\
\hline & - Male & 53.4 & 52.9 & 50.9 & 52.3 \\
\hline \multirow[t]{2}{*}{ Aboriginality } & - Missing & 4.1 & 4.0 & 4.2 & 4.3 \\
\hline & - Aboriginal & 2.2 & 2.4 & 2.7 & 3.0 \\
\hline \multirow[t]{5}{*}{ Marital status } & - Missing & 5.1 & 5.1 & 5.8 & 7.7 \\
\hline & - Divorced & 8.3 & 8.1 & 7.7 & 7.8 \\
\hline & - Married & 48.8 & 48.0 & 43.4 & 42.3 \\
\hline & - Widowed & 33.2 & 34.1 & 38.0 & 36.0 \\
\hline & - Single & 4.7 & 4.7 & 5.1 & 6.3 \\
\hline \multirow[t]{7}{*}{ ARIA+ } & - Missing & 0.6 & 0.6 & 0.9 & 1.0 \\
\hline & - Major cities of Australia & 71.0 & 70.6 & 71.7 & 71.2 \\
\hline & - Inner regional Australia & 13.4 & 13.4 & 12.8 & 12.8 \\
\hline & - Outer regional Australia & 10.7 & 10.8 & 10.1 & 10.1 \\
\hline & - Remote Australia & 2.7 & 2.8 & 2.7 & 2.8 \\
\hline & - Very remote Australia & 1.5 & 1.6 & 1.6 & 1.9 \\
\hline & - Migratory & 0.1 & 0.1 & 0.1 & 0.1 \\
\hline SEIFA - & - Missing & 0.7 & 0.8 & 1.0 & 1.2 \\
\hline \multirow[t]{5}{*}{ IRSD } & - Most disadvantaged & 17.1 & 17.2 & 17.6 & 17.7 \\
\hline & - More disadvantaged & 15.7 & 15.7 & 15.8 & 15.8 \\
\hline & - Average & 14.4 & 14.5 & 14.1 & 14.1 \\
\hline & - Less disadvantaged & 13.8 & 13.8 & 13.5 & 13.6 \\
\hline & - Least disadvantaged & 38.1 & 38.1 & 38.0 & 37.6 \\
\hline
\end{tabular}

ARIA+: Area remoteness, based on 2001 Census boundaries. SEIFA : Socio-economic Indices for Areas, based 2001 Census. IRSD: SEIFA Index of Relative Social Disadvantage. 


\section{Palliative care and place of death}

\section{Key points}

1. About one third of the minimal constituency died in their usual place of residence, about half died in hospital, and the remainder died in hospices, residential aged care services and elsewhere. Similar results were found for the mid-range and maximal constituencies.

2. Specialist palliative care services affected where people died. People who did not receive specialist palliative care services were much more likely to die in hospital or in an aged care facility than people who received specialist palliative care services.

Objective three was to determine where people in the Western Australian palliative care constituencies die, and the effects of receiving palliative care during the last 12 months of life on place of death. First, place of death was determined for people in all three constituencies, and the proportions of people in the population who died in their usual place of residence, in hospitals, hospices, aged care facilities and elsewhere were calculated. Second, patterns of SPCS were examined for people in the minimal constituency in terms of whether it was homebased, hospital-based, both or neither. The place of death of people who did and did not receive these various SPCS were determined and odds ratios were calculated.

\section{Place of death for people in the palliative care constituencies}

Table 5 shows the proportions of people who died in their usual place of residence and in a place other than their usual place of residence. Table 5 subdivides places other than the usual place of residence into hospitals, hospices, residential aged care facilities and other places. Approximately one third of people in each constituency died in their usual place of residence, about half died in hospital, and the remainder died in hospices, residential aged care services and elsewhere.

Table 5: Proportions of people from each of the palliative care constituencies by place of death from 1 July 2000 to 31 December 2002

\begin{tabular}{llcc}
\hline & $\begin{array}{l}\text { Minimal } \\
(\mathbf{n = 1 3 , 4 5 3 )}\end{array}$ & $\begin{array}{c}\text { Constituency } \\
\text { Mid-range } \\
(\mathbf{n = 1 4 , 9 1 9 )}\end{array}$ & $\begin{array}{l}\text { Maximal } \\
(\mathbf{n = 2 4 , 0 3 2})\end{array}$ \\
\hline Usual place of residence & 32.3 & 30.0 & 37.0 \\
& & & \\
Other than usual place of residence & 67.7 & 70.0 & 63.0 \\
Hospital & 51.0 & 54.5 & 49.0 \\
Hospice & 10.7 & 9.8 & 6.1 \\
Residential aged care facility & 3.2 & 3.1 & 4.1 \\
Other & 2.8 & 2.6 & 3.8 \\
\hline Total & 100.0 & 100.0 & 100.0 \\
\hline
\end{tabular}




\section{Effects of receiving palliative care on place of death}

Table 6 shows the odds of dying in a hospital or a residential aged care facility, depending upon the SPCS received, for people in the minimal constituency. People who received no SPCS were much more likely to die in hospital or in an aged care facility than people who received (a) hospital-based SPCS; (b) home-based SPCS; (c) both home- and hospital-based SPCS; or (d) any type of SPCS (either hospital, home, or both hospital and home).

Table 6: Odds ratios of dying in hospital and residential aged care facility for people who received no SPCS in the minimal constituency from 1 July 2000 to 31 December 2002

\begin{tabular}{lcccc}
\hline & \multicolumn{2}{c}{ Odds of dying in hospital } & \multicolumn{2}{c}{$\begin{array}{c}\text { Odds of dying in a residential } \\
\text { aged care facility }\end{array}$} \\
& OR & $\mathbf{9 5 \%}$ CI & OR & $\mathbf{9 5 \%}$ CI \\
\hline No SPCS versus hospital-based SPCS & 1.50 & 1.08 to 2.08 & 3.57 & 2.38 to 5.55 \\
$\begin{array}{l}\text { No SPCS versus home-based SPCS } \\
\text { On }\end{array}$ & 7.69 & 5.56 to 10.00 & 14.29 & 11.11 to 20.00 \\
$\begin{array}{l}\text { No SPCS versus both hospital- and home- } \\
\text { based SPCS }\end{array}$ & 3.44 & 2.50 to 4.76 & 6.67 & 4.55 to 10.00 \\
$\begin{array}{l}\text { No SPCS versus SPCS (either hospital, } \\
\text { home or both) }\end{array}$ & 3.80 & 3.04 to 4.75 & 9.56 & 7.66 to 11.94 \\
\hline
\end{tabular}




\section{Specialist palliative care delivery patterns for population subgroups}

\section{Key points}

1. In the minimal and mid-range constituencies, two people in five received specialist palliative care services in the last year of life. In the maximal constituency, one in four received specialist palliative care services.

2. Two thirds of the people who died of malignancies received specialist palliative care services, but less than one in ten people who died of non-malignant conditions received specialist palliative care services.

3. The non-malignant conditions most likely to receive specialist palliative care services were HIV/AIDS (50\%), motor neurone disease (35\%), Huntington's disease $(23 \%)$, liver failure $(\mathbf{1 7 \%})$, and renal failure $(\mathbf{1 2 \%})$. SPCS rates for heart failure (9\%), chronic obstructive pulmonary disease (7\%), Parkinson's disease $(4 \%)$ and Alzheimer's disease (3\%) were less than $10 \%$.

4. People were less likely to receive specialist palliative care services if they were aged over 84 years, female, Aboriginal, living in outer regional and more remote areas, or more socioeconomically disadvantaged.

Objective four was to study patterns of SPCS delivery during the last 12 months of life, comparing use between different socio-demographic groups and between people with different causes of death. To answer this objective:

- Levels of use of home-based SPCS and hospital-based SPCS were determined for people in the minimal, mid-range and maximal constituencies.

- People in the minimal constituency were divided into subgroups, depending upon their underlying cause of death, and rates of SPCS use in the last 12 months of life were compared across these subgroups.

- People in all constituencies were divided into subgroups depending on their age, gender, aboriginality, geographical remoteness and socio-economic level. Rates of SPCS were compared across these subgroups using odds ratios.

\section{Current levels of use of specialist palliative care services}

Table 7 shows the proportions of people in the minimal, mid-range and maximal constituencies who received SPCS during the last 12 months of life. In the minimal and mid-range constituencies, roughly $40 \%$ of the population received some type of SPCS, but in the maximal constituency, only $25 \%$ received SPCS. The proportions who received home-based, hospitalbased, and both home and hospital SPCS were similar, with home-based being the most common in all three constituencies, and hospital-based the least. 
Table 7: Proportions of people in each constituency who received each type of SPCS from 1 July 2000 to 31 December 2002

\begin{tabular}{lccc}
\hline & $\begin{array}{c}\text { Minimal } \\
(\mathbf{N}=\mathbf{5 ~ 3 8 1})\end{array}$ & $\begin{array}{c}\text { Constituency } \\
\text { Mid-range } \\
(\mathbf{N}=\mathbf{5 9 6 8})\end{array}$ & $\begin{array}{c}\text { Maximal } \\
(\mathbf{N}=\mathbf{9 6 1 3})\end{array}$ \\
\hline SPCS & 42.7 & 39.3 & 25.3 \\
Home-based only & 15.3 & 14.0 & 9.1 \\
Hospital-based only & 12.5 & 11.7 & 7.7 \\
Both home \& hospital & 14.9 & 13.6 & 8.5 \\
No SPCS & 57.3 & 60.7 & 74.7 \\
\hline
\end{tabular}

\section{Levels of use of specialist palliative care services for people with and without malignancies}

Using the minimal palliative care constituency, the proportions of people who received homebased SPCS, hospital-based SPCS, both and neither were examined, by their condition. Table 8 shows that the rate of SPCS for people dying of malignancies $(67.7 \%)$ was much higher than the rate of SPCS for people dying of non-malignant conditions $(8.2 \%)$.

Table 8: Proportions of people in each group who received SPCS in the last year of life from 1 July 2000 to 31 December $2002(n=13,453)$

\begin{tabular}{llcl}
\hline & Malignancy only & $\begin{array}{l}\text { Non-malignancy } \\
\text { only } \\
(\mathbf{n = 5 , 4 4 6 )}\end{array}$ & $\begin{array}{l}\text { Malignancy and } \\
\text { non-malignancy } \\
(\mathbf{n = 6 0 8})\end{array}$ \\
\hline SPCS & $(\mathbf{n = 7 , 3 9 9 )}$ & 8.2 & 48.2 \\
Home-based only & 67.7 & 3.1 & 20.2 \\
Hospital only & 23.9 & 3.9 & 13.2 \\
Home-based and hospital combined & 18.7 & 1.1 & 14.8 \\
No SPCS & 25.1 & & 51.8 \\
\hline
\end{tabular}

Table 9 shows that the rates of SPCS use for each of the non-malignant conditions was $50 \%$ or less, and that several (heart failure, chronic obstructive pulmonary disease (COPD), Alzheimer's disease, Parkinson's disease) were less than 10\%.

\section{Levels of use of specialist palliative care services for socio-demographic groups}

Crude odds ratios were calculated to show the likelihood of receiving SPCS for each group. These odds ratios were then adjusted for the remaining socio-demographic variables to show the likelihood of receiving SPCS independently of these other variables. Tables 10 to 12 show the following significant effects:

- $\quad$ People aged over 84 years were less likely to receive SPCS than the younger age groups.

- Women were less likely to receive SPCS than men (in the minimal and mid-range constituencies).

- Aboriginal people were less likely to receive SPCS than people who were not Aboriginal.

- People living in outer regional and more remote areas were less likely to receive SPCS than people living in major cities.

- People who were most socioeconomically disadvantaged were less likely to receive SPCS than people who were least disadvantaged. 


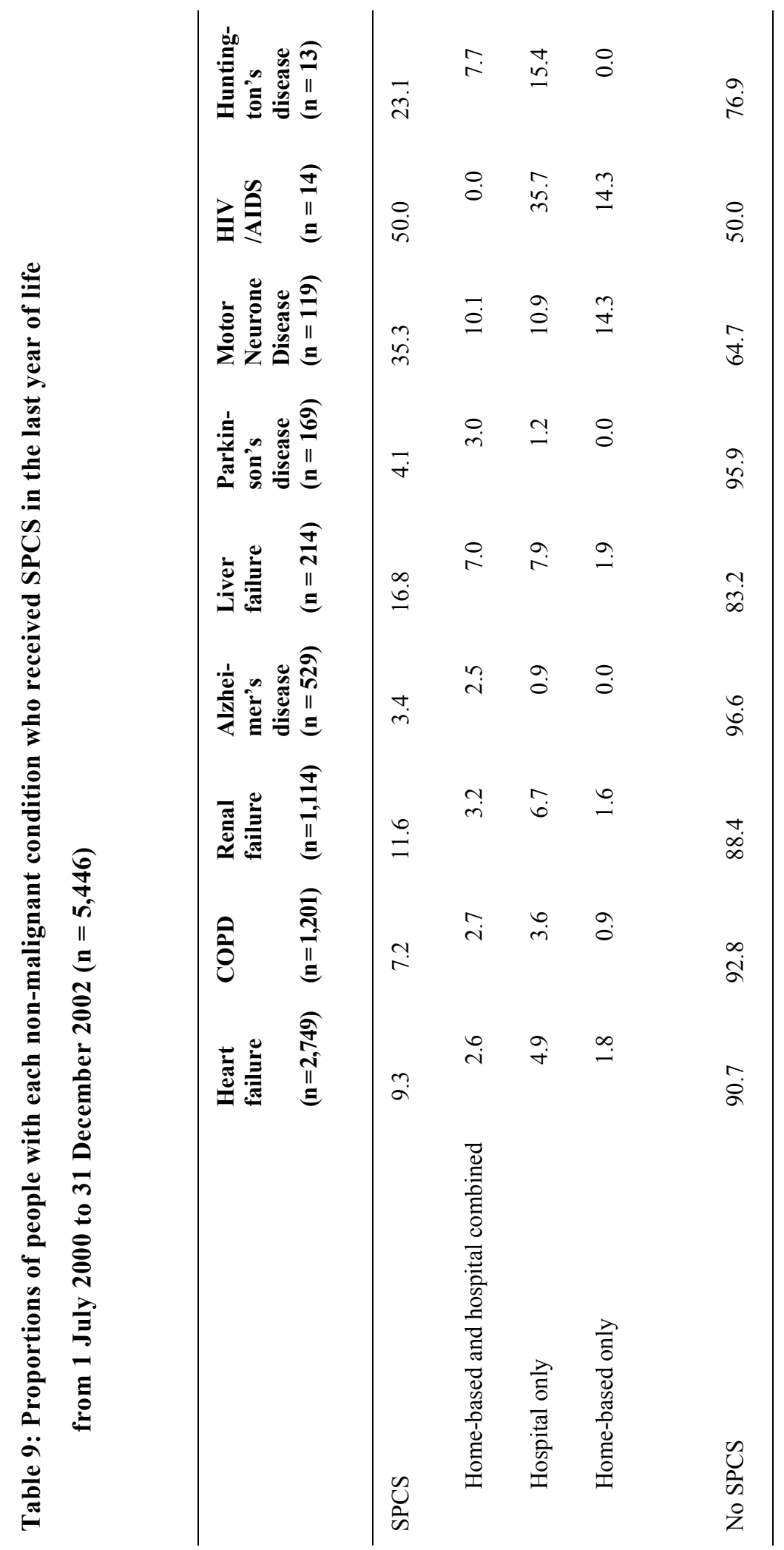


Table 10: Odds ratios for service coverage in the minimal palliative care constituency during the year before death, July 2000 to December 2002

\begin{tabular}{|c|c|c|c|c|}
\hline \multirow[t]{2}{*}{ Variable } & \multicolumn{2}{|c|}{ Crude estimates } & \multicolumn{2}{|c|}{ Adjusted estimates } \\
\hline & OR & $95 \%$ CI & OR & $95 \% \mathrm{CI}$ \\
\hline \multicolumn{5}{|l|}{ Age } \\
\hline - $\quad 0-14$ & 3.16 & $1.74-5.76$ & 3.48 & $1.89-6.39$ \\
\hline - $15-24$ & 5.06 & $2.58-9.94$ & 5.69 & $2.83-11.43$ \\
\hline - $\quad 25-34$ & 6.26 & $4.12-9.49$ & 9.64 & $6.08-15.28$ \\
\hline - $35-44$ & 5.44 & $4.22-7.02$ & 6.18 & $4.73-8.07$ \\
\hline - $45-54$ & 6.20 & $5.26-7.31$ & 7.07 & $5.94-8.41$ \\
\hline - $\quad 55-64$ & 5.79 & $5.08-6.60$ & 6.33 & $5.52-7.27$ \\
\hline - $\quad 64-74$ & 4.00 & $3.58-4.46$ & 4.20 & $3.74-4.71$ \\
\hline - $\quad 75-84$ & 2.72 & $2.45-3.01$ & 2.72 & $2.44-3.03$ \\
\hline - $\quad 85-\mathrm{HIGH}$ & \multicolumn{4}{|c|}{ Referent category } \\
\hline \multicolumn{5}{|l|}{ Gender } \\
\hline - Female & 0.79 & $0.74-0.85$ & 0.91 & $0.84-0.98$ \\
\hline - Male & \multicolumn{4}{|c|}{ Referent category } \\
\hline \multicolumn{5}{|l|}{ Aboriginality } \\
\hline - $\quad$ No & 1.88 & $1.45-2.42$ & 2.19 & $1.64-2.94$ \\
\hline - $\quad$ Yes & \multicolumn{4}{|c|}{ Referent category } \\
\hline \multicolumn{5}{|l|}{ ARIA+ } \\
\hline - $\quad$ Migratory & \multicolumn{2}{|c|}{0.68} & \multicolumn{2}{|r|}{ No data } \\
\hline $\begin{array}{l}\text { Very remote } \\
\text { Australia }\end{array}$ & 0.54 & $0.40-0.73$ & 0.53 & $0.38-0.75$ \\
\hline - $\quad$ Remote Australia & 0.47 & $0.37-0.60$ & 0.44 & $0.34-0.56$ \\
\hline $\begin{array}{l}\text { - Outer regional } \\
\text { Australia }\end{array}$ & 0.65 & $0.58-0.73$ & 0.65 & $0.57-0.74$ \\
\hline $\begin{array}{ll}\text { Inner regional } \\
\text { Australia }\end{array}$ & 0.91 & $0.82-1.00$ & 0.91 & $0.82-1.02$ \\
\hline $\begin{array}{l}\text { Major cities of } \\
\text { Australia }\end{array}$ & \multicolumn{4}{|c|}{ Referent category } \\
\hline \multicolumn{5}{|l|}{ SEIFA - IRSD } \\
\hline - $\quad$ Most disadvantaged & 0.83 & $0.75-0.92$ & 0.84 & $0.75-0.93$ \\
\hline - $\quad$ More disadvantaged & 0.90 & $0.82-1.00$ & 0.91 & $0.82-1.02$ \\
\hline - Average & 0.85 & $0.77-0.95$ & 0.89 & $0.79-1.00$ \\
\hline - $\quad$ Less disadvantaged & 0.97 & $0.87-1.08$ & 0.95 & $0.84-1.07$ \\
\hline - $\quad$ Least disadvantaged & \multicolumn{4}{|c|}{ Referent category } \\
\hline \multicolumn{5}{|c|}{$\begin{array}{l}\text { - Dependent variable }=\text { SPCS from any source (home-based or hospital-based). } \\
\text { - Aboriginality: 'yes' includes people who identified as Aboriginal or Torres Strait Islander } \\
\text { or both. } \\
\text { - ARIA+ categories: based on } 2001 \text { Census boundaries. } \\
\text { - IRSD categories: based on } 2001 \text { Census. }\end{array}$} \\
\hline
\end{tabular}


Table 11: Odds ratios for service coverage in the mid-range palliative care constituency during the year before death, July 2000 to December 2002

\begin{tabular}{|c|c|c|c|c|}
\hline \multirow[t]{2}{*}{ Variable } & \multicolumn{2}{|c|}{ Crude estimates } & \multicolumn{2}{|c|}{ Adjusted estimates } \\
\hline & OR & $95 \% \mathrm{CI}$ & OR & $95 \%$ CI \\
\hline \multicolumn{5}{|l|}{ Age } \\
\hline - $\quad 0-14$ & 2.38 & $1.37-4.14$ & 2.59 & $1.48-4.53$ \\
\hline - $\quad 15-24$ & 4.08 & $2.20-7.57$ & 4.90 & $2.57-9.33$ \\
\hline - $25-34$ & 4.75 & $3.27-6.90$ & 6.98 & $4.65-10.47$ \\
\hline - $35-44$ & 5.06 & $3.98-6.43$ & 5.71 & $4.44-7.34$ \\
\hline - $45-54$ & 6.11 & $5.21-7.15$ & 7.05 & $5.96-8.34$ \\
\hline - $\quad 55-64$ & 5.82 & $5.12-6.60$ & 6.36 & $5.57-7.26$ \\
\hline - $\quad 64-74$ & 4.04 & $3.63-4.49$ & 4.24 & $3.80-4.74$ \\
\hline - $75-84$ & 2.65 & $2.40-2.92$ & 2.66 & $2.40-2.95$ \\
\hline - $\quad 85-\mathrm{HIGH}$ & \multicolumn{4}{|c|}{ Referent category } \\
\hline \multicolumn{5}{|l|}{ Gender } \\
\hline - Female & 0.79 & $0.74-0.84$ & 0.91 & $0.84-0.98$ \\
\hline - Male & \multicolumn{4}{|c|}{ Referent category } \\
\hline \multicolumn{5}{|l|}{ Aboriginality } \\
\hline - $\quad$ No & 1.97 & $1.54-2.51$ & 2.24 & $1.70-2.96$ \\
\hline - Yes & \multicolumn{4}{|c|}{ Referent category } \\
\hline \multicolumn{5}{|l|}{ ARIA+ } \\
\hline - $\quad$ Migratory & \multicolumn{2}{|c|}{0.64} & \multicolumn{2}{|r|}{ No data } \\
\hline $\begin{array}{l}\text { Very remote } \\
\text { Australia }\end{array}$ & 0.51 & $0.38-0.69$ & 0.51 & $0.36-0.70$ \\
\hline - $\quad$ Remote Australia & 0.46 & $0.37-0.58$ & 0.44 & $0.34-0.55$ \\
\hline $\begin{array}{ll}\text { - Outer regional } \\
\text { Australia }\end{array}$ & 0.66 & $0.59-0.74$ & 0.65 & $0.57-0.73$ \\
\hline $\begin{array}{ll}\text { - Inner regional } \\
\text { Australia }\end{array}$ & 0.92 & $0.83-1.01$ & 0.92 & $0.83-1.02$ \\
\hline $\begin{array}{l}\text { Major cities of } \\
\text { Australia }\end{array}$ & \multicolumn{4}{|c|}{ Referent category } \\
\hline \multicolumn{5}{|l|}{ SEIFA - IRSD } \\
\hline - Most disadvantaged & 0.84 & $0.76-0.92$ & 0.84 & $0.76-0.94$ \\
\hline - $\quad$ More disadvantaged & 0.91 & $0.82-1.00$ & 0.91 & $0.82-1.02$ \\
\hline - Average & 0.87 & $0.79-0.96$ & 0.92 & $0.82-1.03$ \\
\hline - $\quad$ Less disadvantaged & 0.99 & $0.90-1.10$ & 0.97 & $0.87-1.09$ \\
\hline - Least disadvantaged & \multicolumn{4}{|c|}{ Referent category } \\
\hline \multicolumn{5}{|c|}{$\begin{array}{l}\text { - Dependent variable = SPCS from any source (home-based or hospital-based). } \\
\text { - Aboriginality: 'yes' includes people who identified as Aboriginal or Torres Strait Islander } \\
\text { or both. } \\
\text { - ARIA+ categories: based on } 2001 \text { Census boundaries. } \\
\text { - IRSD categories: based on } 2001 \text { Census. }\end{array}$} \\
\hline
\end{tabular}


Table 12: Odds ratios for service coverage in the maximal palliative care constituency during the year before death, July 2000 to December 2002

\begin{tabular}{|c|c|c|c|c|}
\hline \multirow[t]{2}{*}{ Variable } & \multicolumn{2}{|c|}{ Crude estimates } & \multicolumn{2}{|c|}{ Adjusted estimates } \\
\hline & OR & 95\% CI & OR & $95 \% \mathrm{CI}$ \\
\hline \multicolumn{5}{|l|}{ Age } \\
\hline - $\quad 0-14$ & 1.17 & $0.75-1.82$ & 1.44 & $0.91-2.28$ \\
\hline - $15-24$ & 2.80 & $1.65-4.73$ & 3.45 & $2.00-5.92$ \\
\hline - $\quad 25-34$ & 3.58 & $2.60-4.92$ & 5.32 & $3.79-7.47$ \\
\hline - $35-44$ & 4.02 & $3.29-4.92$ & 4.95 & $4.01-6.11$ \\
\hline - $45-54$ & 5.72 & $5.00-6.55$ & 6.70 & $5.82-7.73$ \\
\hline - $\quad 55-64$ & 6.07 & $5.44-6.78$ & 6.74 & $6.00-7.56$ \\
\hline - $\quad 64-74$ & 4.45 & $4.05-4.89$ & 4.73 & $4.28-5.22$ \\
\hline - $\quad 75-84$ & 2.74 & $2.50-2.99$ & 2.78 & $2.53-3.04$ \\
\hline - $\quad 85-\mathrm{HIGH}$ & \multicolumn{4}{|c|}{ Referent category } \\
\hline \multicolumn{5}{|l|}{ Gender } \\
\hline - Female & 0.76 & $0.71-0.80$ & 0.95 & $0.89-1.01$ \\
\hline - Male & \multicolumn{4}{|c|}{ Referent category } \\
\hline \multicolumn{5}{|l|}{ Aboriginality } \\
\hline - $\quad$ No & 2.03 & $1.63-2.54$ & 2.47 & $1.92-3.18$ \\
\hline - $\quad$ Yes & \multicolumn{4}{|c|}{ Referent category } \\
\hline \multicolumn{5}{|l|}{ ARIA+ } \\
\hline - $\quad$ Migratory & \multicolumn{2}{|c|}{0.74} & \multicolumn{2}{|r|}{ No data } \\
\hline $\begin{array}{ll}\text { - } & \text { Very remote } \\
& \text { Australia }\end{array}$ & 0.59 & $0.45-0.76$ & 0.62 & $0.46-0.83$ \\
\hline - $\quad$ Remote Australia & 0.54 & $0.44-0.67$ & 0.50 & $0.40-0.62$ \\
\hline $\begin{array}{l}\text { - Outer regional } \\
\text { Australia }\end{array}$ & 0.80 & $0.72-0.89$ & 0.79 & $0.71-0.88$ \\
\hline $\begin{array}{ll}\text { Inner regional } \\
\text { Australia }\end{array}$ & 1.03 & $0.94-1.12$ & 1.03 & $0.94-1.13$ \\
\hline $\begin{array}{l}\text { Major cities of } \\
\text { Australia }\end{array}$ & \multicolumn{4}{|c|}{ Referent category } \\
\hline \multicolumn{5}{|l|}{ SEIFA - IRSD } \\
\hline - $\quad$ Most disadvantaged & 0.87 & $0.80-0.95$ & 0.83 & $0.76-0.91$ \\
\hline - $\quad$ More disadvantaged & 0.92 & $0.84-1.00$ & 0.88 & $0.80-0.97$ \\
\hline - Average & 0.94 & $0.86-1.03$ & 0.92 & $0.84-1.02$ \\
\hline - $\quad$ Less disadvantaged & 1.03 & $0.94-1.13$ & 0.98 & $0.89-1.09$ \\
\hline - $\quad$ Least disadvantaged & \multicolumn{4}{|c|}{ Referent category } \\
\hline \multicolumn{5}{|c|}{$\begin{array}{l}\text { - Dependent variable }=\text { SPCS from any source (home-based or hospital-based). } \\
\text { - Aboriginality: 'yes' includes people who identified as Aboriginal or Torres Strait Islander } \\
\text { or both. } \\
\text { - ARIA+ categories: based on } 2001 \text { Census boundaries. } \\
\text { - IRSD categories: based on } 2001 \text { Census. }\end{array}$} \\
\hline
\end{tabular}




\section{Home- and hospital-based specialist palliative care}

Key points

1. One person in four in the minimal and mid-range constituencies, and one in six in the maximal constituency had a hospital admission for specialist palliative care services during the last 12 months of life. People spent, on average, between 17 and 18 days in hospital receiving specialist palliative care services during the last 12 months of life.

2. Nine people out of $\mathbf{1 0}$ in the minimal and mid-range constituencies, and eight people out of 10 in the maximal constituency were admitted to hospital in their last year for hospital admissions not involving specialist palliative care services. The average days spent in hospital for non-palliative service care was between 34 and 36.

3. Slightly less than one person in three in the minimal and mid-range constituencies, or one in six in the maximal constituency received home-based specialist palliative care services in the last 12 months of life.

4. People who received any type of specialist palliative care services (hospital only, home only, or both hospital and home) spent on average 5 days more in hospital but 6 days less in non-palliative service hospital admissions.

Objective five was to study the relationships between home-based and hospital SPCS for people during the last 12 months of life. To answer this objective, use of SPCS was divided into hospital-based SPCS and home-based SPCS, and each of these is considered separately. The relationship between SPCS and hospital admissions is then considered.

\section{Hospital-based specialist palliative care services}

Table 13 shows hospital-based SPCS use for each of the three constituencies. One person in four (in the minimal and mid-range constituencies) or one in six (in the maximal constituency) had a SPCS hospital admission in the last 12 months of life. Across constituencies, the average number of admissions was 1.6 and the average number of days spent in hospital receiving SPCS was between 17 and 18. This represents an average length of stay of 11.1 days, slightly less than the 12.3 days reported by the Australian Institute of Health and Welfare (AIHW) ${ }^{66}$.

Nine people out of 10 in the minimal and mid-range constituencies, and eight people out of 10 in the maximal constituency were admitted to hospital in their last year for non-SPCS hospital admissions, and the average non-SPCS days spent in hospital was 34 to 36 days per person. A comparison of those who did receive hospital-based SPCS with those who did not, in terms of their non-SPCS hospital admissions, showed only one significant difference: in the minimal constituency the average length of stay was greater for people who had had no SPCS hospital admission $($ mean difference $=7.4$ days, $95 \%$ CI $6.1-8.7, \mathrm{p}<0.0001$ ). 
Table 13: Hospital use in the 12 months before death for each palliative care constituency, July 2000 to December 2002

\begin{tabular}{|c|c|c|c|}
\hline & $\begin{array}{l}\text { Minimal estimate } \\
\quad(\mathrm{n}=13,453)\end{array}$ & $\begin{array}{l}\text { Mid-range estimate } \\
\quad(\mathrm{n}=14,919)\end{array}$ & $\begin{array}{l}\text { Maximal estimate } \\
\quad(\mathrm{n}=24,032)\end{array}$ \\
\hline \multicolumn{4}{|l|}{ SPCS hospital admissions } \\
\hline $\begin{array}{l}\text { Proportion of people with at least one } \\
\text { admission }\end{array}$ & $27.4 \%$ & $25.3 \%$ & $16.2 \%$ \\
\hline Average number of admissions & 1.6 & 1.6 & 1.6 \\
\hline Average number of bed days/person & 17.6 & 17.4 & 17.2 \\
\hline \multicolumn{4}{|l|}{ Other hospital admissions - total } \\
\hline $\begin{array}{l}\text { Proportion of people with at least one } \\
\text { admission }\end{array}$ & $88.3 \%$ & $89.4 \%$ & $79.9 \%$ \\
\hline Average number of admissions & 7.0 & 6.6 & 5.6 \\
\hline Average number of bed days/person & 36.0 & 35.6 & 33.9 \\
\hline \multicolumn{4}{|c|}{ Other hospital admissions for people who had a SPCS admission (breakdown of total) } \\
\hline $\begin{array}{l}\text { Proportion of people with at least one } \\
\text { admission }\end{array}$ & $94.0 \%$ & $93.9 \%$ & $93.7 \%$ \\
\hline Average number of admissions & 6.7 & 6.6 & 6.6 \\
\hline Average number of bed days/person & 30.8 & 30.9 & 31.0 \\
\hline \multicolumn{4}{|c|}{ Other hospital admissions for people who did not have a SPCS admission (breakdown of total) } \\
\hline $\begin{array}{l}\text { Proportion of people with at least one } \\
\text { admission }\end{array}$ & $86.2 \%$ & $87.9 \%$ & $77.2 \%$ \\
\hline Average number of admissions & 7.1 & 6.6 & 5.4 \\
\hline Average number of bed days/person & 38.2 & 37.3 & 34.6 \\
\hline
\end{tabular}

\section{Home-based specialist palliative care services}

Use of home-based SPCS is shown in Table 14. Less than one person in three (in the minimal and mid-range constituencies) or one in six (in the maximal constituency) received home-based SPCS in the last 12 months of life. Fifty-eight percent of these people also received homebased non-SPCS (e.g., personal care, domestic assistance, respite). People who received no home-based SPCS were less likely to receive home-based non-SPCS services (only about one in four did so), but received 48.1 more visits (95\% CI $41.8-54.4$ visits, $\mathrm{p}<0.001)$ and 28.4 hours more home-based, non-specialist palliative care (95\% CI $23.9-32.8$ hours, $p<0.001)$. 
Table 14: Use of home-based care the 12 months before death for each palliative care constituency estimates, July 2000 to December 2002

\begin{tabular}{|c|c|c|c|}
\hline & $\begin{array}{l}\text { Minimal estimate } \\
\quad(\mathrm{n}=13,453)\end{array}$ & $\begin{array}{l}\text { Mid-range estimate } \\
\quad(\mathrm{n}=14,919)\end{array}$ & $\begin{array}{l}\text { Maximal estimate } \\
\quad(\mathrm{n}=24,032)\end{array}$ \\
\hline \multicolumn{4}{|l|}{ Home-based SPCS } \\
\hline $\begin{array}{l}\text { Proportion of people using home-based } \\
\text { SPCS }\end{array}$ & $30.3 \%$ & $27.6 \%$ & $17.7 \%$ \\
\hline Average visits & 46.6 & 46.4 & 45.7 \\
\hline $\begin{array}{l}\text { Average client attributable time } \\
\text { (hours) }\end{array}$ & 30.8 & 30.7 & 30.2 \\
\hline \multicolumn{4}{|l|}{ Other home-based services - total } \\
\hline $\begin{array}{l}\text { Proportion of people using other home- } \\
\text { based services }\end{array}$ & $35.8 \%$ & $34.7 \%$ & $28.0 \%$ \\
\hline Average visits & 47.3 & 50.2 & 59.5 \\
\hline $\begin{array}{l}\text { Average client attributable time } \\
\text { (minutes) }\end{array}$ & 31.0 & 33.0 & 39.6 \\
\hline \multicolumn{4}{|c|}{ Other home-based services for people who also received home-based SPCS (breakdown of total) } \\
\hline Proportion of people using SPCS & $58.6 \%$ & $58.6 \%$ & $58.4 \%$ \\
\hline Average visits & 23.1 & 23.3 & 24.3 \\
\hline $\begin{array}{l}\text { Average client attributable time } \\
\text { (hours) }\end{array}$ & 16.6 & 16.9 & 17.6 \\
\hline \multicolumn{4}{|c|}{ Other home-based services for people who did not receive home-based SPCS (breakdown of total) } \\
\hline Proportion of people using SPCS & $25.9 \%$ & $25.5 \%$ & $21.5 \%$ \\
\hline Average visits & 71.2 & 73.7 & 80.0 \\
\hline Average client attributable time (hours) & 45.0 & 47.2 & 52.4 \\
\hline \multicolumn{4}{|c|}{$\begin{array}{l}\text { Notes: } \\
\text { Other home-based services exclude codes PAL and PAL. Additionally, the service coordination and } \\
\text { assessment component of providing care has been excluded (code SA). }\end{array}$} \\
\hline Total client attributable time includes bc & ome and out of hom & direct care time. & \\
\hline
\end{tabular}

\section{Specialist palliative care services and hospitalisations}

The effects of receiving SPCS on number of hospital admissions and days was examined, controlling for the possible confounding effects of age, gender, aboriginality, social disadvantage and geographical remoteness. The results showed that people who received SPCS from any source spent on average 5.3 days more in hospital (95\% CI $3.6-7.0$ days), but 5.8 days less in non-SPCS hospital admissions (95\% CI 4.2 - 7.4 days less). People who received home-based SPCS spent on average 4.4 days less in hospital (95\% CI $2.6-6.1$ days less), but 3.9 days more in SPCS admissions (95\% CI $3.4-4.5)$. 


\section{A projected costing model for specialist palliative care}

Key points

1. A costing model was developed for use of hospital- and home-based specialist palliative care services by $50 \%, 75 \%, 90 \%$ and $100 \%$ of each palliative care constituency.

2. If $50 \%$ of the minimal or mid-range constituencies were to receive hospital-based specialist palliative care services, the current Western Australian budget allocation for specialist palliative care services would be fully or almost fully spent.

3. If $50 \%$ of the minimal or mid-range constituencies were to receive home-based specialist palliative care services, this would cost two to three times as much as is currently allocated for the purpose in Western Australia.

Objective six was to develop a model to estimate the cost of an increased demand on specialist palliative care services.

This analysis estimated the cost of SPCS use under four scenarios, which represented increased demand for SPCS: SPCS use by $50 \%, 75 \%, 90 \%$ or $100 \%$ of each palliative care constituency. The estimations are based on the assumptions that people who did not receive SPCS during the study period would have had similar use patterns (e.g., length of stay) to actual users.

\section{Costing model for hospital-based specialist palliative care services}

Table 15 shows the effect of increased demand on the use of hospital-based SPCS. The annual cost of providing hospital-based SPCS in the period July 2000 to December 2002 was $\$ 9.2$ to $\$ 9.5 \mathrm{M}$, depending on how the palliative care constituency is defined. If half of all people who comprised the minimal or mid-range definitions of the palliative care constituency had received hospital-based SPCS, this cost would have increased to $\$ 16.8$ to $\$ 18.4 \mathrm{M}$ per annum, which is approximately equivalent to the $\$ 18 \mathrm{M}$ directed to palliative care in Western Australia $^{67}$.

It should be noted that the estimated cost of hospital care has been based on a purchase price of $\$ 355$ per bed day reported by a Western Australian Department of Health official. However, anecdotal reports from providers indicate that the actual cost of providing SPCS is approximately $30 \%$ higher than the purchase price. 
Table 15: Estimated costs of increased demand on the average per annum use of hospitalbased SPCS in the last year of life

\begin{tabular}{|c|c|c|c|c|c|}
\hline & \multirow{3}{*}{$\begin{array}{r}\text { Actual use of } \\
\text { hospital- based } \\
\text { SPCS }\end{array}$} & \multirow{2}{*}{\multicolumn{4}{|c|}{$\begin{array}{l}\text { Estimated use of hospital-based SPCS if } \\
\text { demand increased } \\
(\% \text { palliative care constituency needing SPCS })\end{array}$}} \\
\hline & & & & & \\
\hline & & $50 \%$ & $75 \%$ & $90 \%$ & $100 \%$ \\
\hline \multicolumn{6}{|l|}{ Minimal estimate $(\mathrm{n}=5,381$ per annum $)$} \\
\hline No. of people with at least 1 admission & $1,476(27.4 \%)$ & 2,694 & 4,040 & 4,848 & 5,381 \\
\hline Total number of admissions & 2,336 & 4,263 & 6,394 & 7,673 & 8,526 \\
\hline Total number of bed days & ${ }^{1} 25,901$ & 47,264 & 70,884 & 85,076 & 94,528 \\
\hline Estimated cost per annum & $\$ 9.2 \mathrm{M}$ & $\$ 16.8 \mathrm{M}$ & $\$ 25.2 \mathrm{M}$ & $\$ 30.2 \mathrm{M}$ & $\$ 33.6 \mathrm{M}$ \\
\hline \multicolumn{6}{|l|}{ Mid-range estimate $(\mathrm{n}=5,968$ per annum) } \\
\hline No. of people with at least 1 admission & $1,510(25.3 \%)$ & 2.984 & 4,476 & 5,371 & 5,968 \\
\hline Total number of admissions & 2,376 & 4,696 & 7,043 & 8,452 & 9,391 \\
\hline Total number of bed days & 26,188 & 51,755 & 77,632 & 93,159 & 103,510 \\
\hline Estimated cost per annum & $\$ 9.3 \mathrm{M}$ & $\$ 18.4 \mathrm{M}$ & $\$ 27.6$ & $\$ 33.1 \mathrm{M}$ & $\$ 36.7 \mathrm{M}$ \\
\hline \multicolumn{6}{|l|}{ Maximal estimate ( $n=9,613$ per annum) } \\
\hline No. of people with at least 1 admission & $1,588(16.2 \%)$ & 4,809 & 7,213 & 8,656 & 9,613 \\
\hline Total number of admissions & 2,436 & 7,518 & 11,278 & 13,533 & 15,037 \\
\hline Total number of bed days & 26,847 & 82,861 & 124,292 & 149,151 & 165,724 \\
\hline Estimated cost per annum & $\$ 9.5 \mathrm{M}$ & $\$ 29.4 \mathrm{M}$ & $\$ 44.1 \mathrm{M}$ & $\$ 52.9 \mathrm{M}$ & $\$ 58.8 \mathrm{M}$ \\
\hline
\end{tabular}

\section{Costing model for home-based specialist palliative care services}

Table 16 shows the effect of increased demand on the use of home-based SPCS. The annual cost of providing home-based SPCS in the period July 2000 to December 2002 was $\$ 5.5$ to $\$ 5.6 \mathrm{M}$, depending on how the palliative care constituency was defined. If half of all people who comprised the minimal or mid-range definitions of the palliative care constituency had received home-based SPCS, this cost would have increased to $\$ 9.1$ to $\$ 15.9 \mathrm{M}$ per annum. The costing of home-based SPCS is based on a rate of $\$ 110$ per hour ${ }^{68}$. Unlike the purchase price reported for hospital-based SPCS, the cost for home-based SPCS represents the true cost of providing one hour of care.

\footnotetext{
${ }^{1}$ Estimations are based on the assumption that people who are not currently receiving SPCS will have similar use patterns (e.g., length of stay) to actual users. Rounding error is present in some cells.

$\mathrm{n}=$ Average per annum count calculated by dividing July 2000 to December 2002 count by 2.5 (years).
} 
Table 16: Estimated costs of increased demand on the average per annum use of homebased SPCS in the last year of life ${ }^{1}$

\begin{tabular}{lrrrrr}
\hline & $\begin{array}{c}\text { Actual use of } \\
\text { home based } \\
\text { SPCS }\end{array}$ & \multicolumn{4}{c}{$\begin{array}{c}\text { Estimated use of home-based SPCS if } \\
\text { demand increased }\end{array}$} \\
& & $50 \%$ & $75 \%$ & $90 \%$ & $100 \%$ \\
\hline Minimal estimate ( $\mathrm{n}=5,381$ per annum) & & & & & \\
\hline No. of people using home-based SPCS & $1,628(30.3 \%)$ & 2,686 & 4,030 & 4,836 & 5,381 \\
Total visits & 75,921 & 125,282 & 187,923 & 225,508 & 250,564 \\
Total client attributable time (hours) & 50,157 & 82,767 & 124,150 & 148,981 & 165,535 \\
Estimated cost per annum & $\$ 5.5 \mathrm{M}$ & $\$ 9.1 \mathrm{M}$ & $\$ 13.6 \mathrm{M}$ & $16.4 \mathrm{M}$ & $\$ 18.2 \mathrm{M}$ \\
\hline Mid-range estimate ( $=5,968$ per annum) & & & & & \\
\hline No. of people using home-based SPCS & $1,648(27.6 \%)$ & 2,985 & 4,478 & 5,374 & 5,968 \\
Total visits & 76,540 & 138,659 & 207,989 & 249,587 & 277,319 \\
Total client attributable time (hours) & 50,522 & 91,525 & 137,288 & 164,746 & 183,051 \\
Estimated cost per annum & $\$ 5.6 \mathrm{M}$ & $\$ 10.1 \mathrm{M}$ & $\$ 15.1 \mathrm{M}$ & $\$ 18.1 \mathrm{M}$ & $20.1 \mathrm{M}$ \\
\hline Maximal estimate ( $\mathrm{n}=9,613$ per annum) & & & & & \\
\hline No. of people using home-based SPCS & $1,697(17.7 \%)$ & 4,794 & 7,191 & 8,629 & 9,588 \\
Total visits & 77,572 & 219,130 & 328,695 & 394,434 & 438,260 \\
Total client attributable time (hours) & 51,184 & 144,588 & 216,881 & 260,258 & 289,175 \\
Estimated cost per annum & $\$ 5.6 \mathrm{M}$ & $\$ 15.9 \mathrm{M}$ & $\$ 23.8 \mathrm{M}$ & $\$ 28.6 \mathrm{M}$ & $\$ 31.8 \mathrm{M}$ \\
\hline
\end{tabular}

\section{Costing model for both hospital- and home-based specialist palliative care services}

Figure 3 shows the total cost of SPCS (hospital- and home-based combined) for each of the constituencies, illustrating actual use, $50 \%$ use, $75 \%$ use and $90 \%$ use, as compared with the budget allocation of $\$ 18 \mathrm{M}$. It is evident that increasing the accessibility of SPCS to people in the various constituencies proposed in this report would far exceed the current budget allocation for SPCS. If $50 \%$ of the minimal constituency required both hospital- and homebased SPCS, the budget would be $\$ 25.9 \mathrm{M}$ and would thus exceed the current budget by over $40 \%$.

\footnotetext{
${ }^{1}$ Estimations are based on the assumption that people who are not currently receiving SPCS will have similar use patterns (e.g., number of visits) to actual users. Rounding error is present in some cells. $\mathrm{n}=$ Average per annum count calculated by dividing July 2000 to December 2002 count by 2.5 (years).
} 
Figure 3: Estimated costs of total SPCS by comparison with the total PC budget.

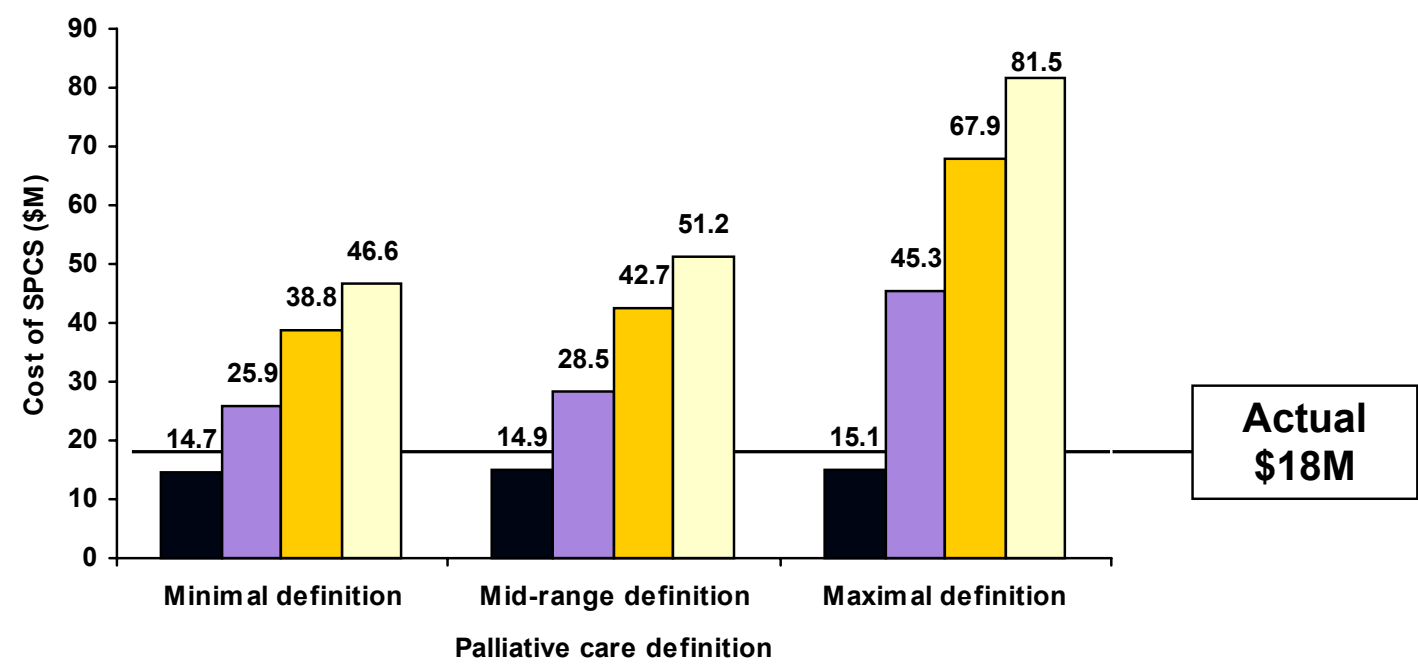

- Actual $\square \mathbf{5 0 \%} \square \mathbf{7 5} \% \square \mathbf{9 0 \%}$ 


\section{Section 5 Limitations}

The main limitations of the present study were as follows:

1. The constituencies proposed in this study were limited by the data available in the population databases, and could not take into account factors such as the severity and nature of symptoms, family circumstances or individual preferences for specialist palliative care services (SPCS). These constituencies are therefore necessarily at least partly condition-based, and are, as such, potential needs-based.

2. The study may underestimate SPCS use by targeting designated SPCS providers. It has been suggested that palliative care is best integrated into general treatment and provided by family, friends and healthcare professionals ${ }^{69}$. However, this level of palliative care is not currently possible to quantify in a population database and would not have been identified in the present study.

3. The present study is dependent on the accuracy with which the causes of death are specified on death certificates. There is evidence that some conditions, such as Alzheimer's disease ${ }^{70}$ and chronic obstructive pulmonary disease $\mathrm{e}^{71-72}$, may be underreported on death certificates.

4. Families of people who are dying often carry a large financial burden ${ }^{44}$, and in estimating the costs of SPCS, this study did not take account of the costs borne by families.

5. The period of the study was restricted to only 30 months owing to two factors. One was a changeover from ICD-9 to ICD-10 in the records system being used. The other was that the reliability of the data from Silver Chain has been established only in recent years. Therefore, the forecasting model could not be extended over a longer period of time.

6. This study was restricted to Western Australia and the results may not be generalisable to other countries or other states of Australia. While Western Australia has an internationally recognized Data Linkage System that provides unique epidemiological study opportunities, other states of Australia will not be able to replicate this study easily. In other states and countries there are also usually multiple providers of SPCS, whereas in Western Australia, Silver Chain is almost the sole provider of home-based palliative care in the metropolitan area.

7. The present study shows the current patterns of SPCS provision in Western Australia, but not the reasons for these patterns. This is recommended as a subject for further research. 


\section{Section 6 Conclusions and implications}

Our study provides unique information on the health care use of people in the last year of their lives, that is unprecedented in Australia. There is, to date, no universally accepted normative benchmark for defining palliative care needs at the population level. Previous studies have been descriptive and dependent on limited methodologies. Our study uses, for the first time, a population-based empirical analysis that defines unmet need. By utilising the Western Australian Linked Database to present trends in service utilisation, the study has identified gaps in the provision of care to terminally ill people in Western Australia.

Having identified these gaps, we believe that policy makers are now better able to address the needs of those most disadvantaged. It is particularly notable that a significant proportion of the people who died in the period July 2000 to December 2002 did not receive specialist palliative care services. Traditionally, people who die of cancer receive palliative care. It is not surprising that this group was well serviced with specialist palliative care, compared to people suffering from other life-limiting conditions. Despite this, one third of people who died of cancer in this time period did not access specialist palliative care services. Previous disadvantage in respect to provision of specialist palliative care services has been noted. This population-based study notes the exact extent of this potential need.

The study demonstrates a strong network of palliative care services once clients are referred to any of the specialist palliative care services in Western Australia. Those who receive specialist palliative care services in hospital are more likely to receive home-based palliative care services and the reverse is also true. Referral to a palliative care service for patients with conditions other than cancer is unlikely to occur, with only eight percent of those people with conditions recognised to be in a minimal constituency for palliative care receiving specialist palliative care services in the period July 2000 to December 2002.

The study assesses the impact of recent advances in palliative care on the use of the acute hospital sector. Increasing palliative care services has the potential to reduce the demand on other hospital beds. While it could be argued that reduced demand for acute hospital beds may only shift costs to palliative care beds, we argue that patients should have access to the most appropriate services for their needs. Costing of hospital beds was beyond the scope of our study. However, individual institutions can cost these figures. In addition, people who received specialist palliative care services were less likely to die in hospital. Costing of home services versus acute hospital care is needed to fully appreciate the importance of these findings.

To develop our forecasting model, we used a figure based on the total expenditure on palliative in Western Australia. If half of the people from the minimal dataset accessed hospital specialist palliative care services this would use most, if not all, of the allocated budget for palliative care in any one year. This is only hospital-based services. Our study demonstrates that homebased specialist palliative care is less costly than hospital care. The shift to home-based palliative care would not only ease expensive acute hospital care, but also possibly provide people more appropriate care at the end of their lives. 


\section{Section $7 \quad$ Recommendations}

\section{Recommendations for practice}

The palliative care providers consulted in this study believe that specialist palliative care services need to be extended to people with non-malignant, life-limiting conditions. This view is also supported by the palliative care literature. Although this view is widely held, the most important finding of our study shows that most people dying of conditions other than cancer in Western Australia do not receive specialist palliative care. A number of issues need to be addressed in order to encourage action:

- $\quad$ Rather than merely increasing government spending on palliative care, shifting resources from acute to palliative care services, while contentious, may be more appropriate.

- The possible reluctance to refer patients with terminal non-malignant conditions to specialist palliative care services, and to treat these people within the services, needs to be addressed, possibly with a targeted educational campaign.

- Further research is needed to compare the end-of-life experiences of people with malignant conditions who do and do not receive specialist palliative care, in order to explore a needs-based approach to palliative care provision.

- Public dissemination is needed to draw attention to the broad constituency for palliative care so that people with conditions other than cancer are aware of appropriate supportive services for people nearing the end of their lives.

In support of The Palliative Care Service Provision in Australia Planning Guide (2003), we have provided a refinement of figures that can be used to project professional staffing needs for palliative care services in the future. We therefore recommend that Palliative Care Australia consider the following guidelines for a forecasting model:

- a three-tiered approach to calculating the palliative care constituency (minimal, midrange and maximal, although, conceivably the mid-range could be adjusted with advice from clinicians and epidemiologists); and

- $\quad$ use of Western Australian figures, derived from our study, to determine provision of services in Western Australia and inform provision of services in other states.

We have identified groups in the population who are the least well-serviced for specialist palliative care, that is, those who are:

- $\quad$ aged older than 84 years;

- Aboriginal;

- $\quad$ live in geographically remote areas; and

- $\quad$ socio-economically disadvantaged. 


\section{Recommendations for further research}

We suggest our data be used to support ongoing work that investigates how palliative care can be better implemented in aged care, Aboriginal communities and in geographically remote areas. While palliative care in aged care accommodation is receiving attention, it is notable that the very old (people older than 84) are missing out on palliative care when compared to younger people. Further work should be done to investigate the circumstances of these people as they approach the end of their lives. One area that has not been highlighted to date is the degree to which people who are socioeconomically disadvantaged miss out on receiving palliative care. This is an area that needs further investigation.

The study has raised issues that it could not answer. It has identified that there are factors that influence the use, or non-use, of specialist palliative care services. It may be that:

- $\quad$ people do not know that specialist palliative care services exist;

- those who do know of palliative care believe that it is inappropriate for their circumstances (i.e. they do not believe they are approaching the end of their lives or that their symptoms and concerns warrant specialised services);

- $\quad$ some medical specialists do not refer people to specialist palliative care services;

- $\quad$ specialist palliative care services limit the number of non-cancer based admissions, or

- there are other unidentified factors that influence peoples' non-use of specialist palliative care services.

To address some of these issues the met and unmet needs of terminally ill people in the last 12 months of their lives should be measured and the relative importance of each factor determined. 


\section{References}

1. Potter J, Hami F, Bryan T, Quigley C. Symptoms in 400 patients referred to palliative care services: prevalence and patterns. Palliative Medicine 2003;17:310-314.

2. Higginson IJ. Who needs palliative care? [comment]. Journal of the Royal Society of Medicine 1998;91(11):563-4.

3. Addington-Hall J, Fakhoury W, McCarthy M. Specialist palliative care in nonmalignant disease. Palliative Medicine 1998;12:417-427.

4. Addington-Hall J, Higginson I. Palliative Care for Non-Cancer Patients. Oxford: Oxford University Press, 2001.

5. Ahmed N, Bestall JC, Ahmedzai SH, Payne SA, D. C, Noble B. Systematic review of the problems and issues of accessing specialist palliative care by patients, carers and health and social care professionals. Palliative Medicine 2004;18:525-542.

6. Bradley EH, Fried TR, Kasl SV, Cicchetti DV, Johnson-Hurzeler R, Horwitz SM. Referral of terminally ill patients for hospice: frequency and correlates. Journal of Palliative Care 2000;16(4):20-6.

7. Fox E, Landrum-McNiff K, Zhong Z, Dawson NV, Wu AW, Lynn J. Evaluation of prognostic criteria for determining hospice eligibility in patients with advanced heart, lung, or liver disease. Journal of the American Geriatrics Society 1999;282(17):163845.

8. Seale C. Death from cancer and death from other causes: The relevance of the hospice approach. Palliative Medicine 1991;5:12-19.

9. Field D, Addington-Hall J. Extending palliative care to all? Social Science \& Medicine 1999;48:1271-1280.

10. Mitchell GK. How well do general practitioners deliver palliative care? A systematic review. Palliative Medicine 2002;16(6):457-64.

11. Davidson P, Introna K, Daly J, Paull G, Jarvis R, J A, et al. Cardiorespiratory nurses' perceptions of palliative care in nonmalignant disease: Data for the development of clinical practice. American Journal of Critical Care 2003;12(1):47-53.

12. Murray SA, Boyd K, Kendall M, Worth A, Benton TF, Clausen H. Dying of lung cancer or cardiac failure: prospective qualititative interview study of patients and their carers in the community. British Medical Journal 2002;325:929-933.

13. Currow DC, Abernethy AP, Fazekas BS. Specialist palliative care needs of whole populations: A feasibility study using a novel approach. Palliative Medicine 2004;18:239-247.

14. Lee A, Pang WS. Preferred place of death - A local study of cancer patients and their relatives. Singapore Medical Journal 1998;39(10):447-450.

15. Tang ST, McCorkle R. Determinants of congruence between the preferred and actual place of death for terminally ill cancer patients. Journal of Palliative Care 2003;19(4):230237.

16. Kikule E. A good death in Uganda: Survey needs for palliative care for terminally ill people in urban areas. British Medical Journal 2003;327:192-194.

17. Higginson IJ, Astin P, Dolan S. Where do cancer patients die? Ten-year-trends in the place of death of cancer patients in England. Palliative Medicine 1998;12:353-363. 
18. Bruera E, Sweeney C, Russell N, Willey JS, Palmer JL. Place of death of Houston area residents with cancer over a two-year period. Journal of Pain \& Symptom Management 2003;26(1):637-643.

19. Higginson IJ, Thompson M. Children and young people who die from cancer: Epidemiology and place of death in England (1995-9). British Medical Journal 2003;327:478-479.

20. De Conno F, Caraceni A, Groff L, Brunelli C, Donati I, Tamburini M, et al. Effect of home care on the place of death of advanced cancer patients. European Journal of Cancer 1996;32A(7):1142-1147.

21. Constantini M, Blazi D, Garronec E, Orlandini C, Parodi S, Vercelli M, et al. Geographical variations of place of death among Italian communities suggest an inappropriate hospital use in the terminal phase of cancer disease. Public Health 2000;114:15-20.

22. Fukui S, Kawagoe H, Masako S, Noriko N, Hiroko N, Toshie M. Determinants of the place of death among terminally ill cancer patients under home hospice care in Japan. Palliative Medicine 2003;17:445-453.

23. Gatrell AC, Harman JC, Francis BJ, Thomas C, M. MS, McIllmurray M. Place of death: Analysis of cancer deaths in part of North West England. Journal of Public Health Medicine 2003;25(1):53-58.

24. Burge F, Lawson B, Johnston G. Trends in the place of death of cancer patients, 19921997. CMAJ Canadian Medical Association Journal 2003;168(3):265-70.

25. Catalán-Fernández JG, Pons-Sureda O, Recober-Martínez A, Avellà-Mestre A, CarbonerMalberti JM, Benito-Oliver E, et al. Dying of cancer: The place of death and family circumstances. Medical Care 1991;29(9):841-852.

26. Tang ST, McCorkle R. Determinants of place of death for terminal cancer patients. Cancer Investigation 2001;19(2):165-180.

27. Hunt R, McCaul K. Coverage of cancer patients by hospice services, South Australia, 1990 to 1993. Australian \& New Zealand Journal of Public Health 1998;22(1):45-8.

28. Moinpour CM, Polissar L. Factors affecting place of death of hospice and nonhospice cancer patients. American Journal of Public Health 1989;79(11):1549-1551.

29. McWhinney LR, Bass MJ, Orr V. Factors associated with location of death (home or hospital) of patients referred to a palliative care team. Canadian Medical Association Journal 1995;152(3):361-367.

30. Hunt RW, Fazekas BS, Luke CG, Priest KR, Roder DM. The coverage of cancer patients by designated palliative services: a population-based study, South Australia, 1999. Palliative Medicine 2002;16(5):403-9.

31. Burge F, Johnston G, Lawson B, Dewar R, Cummings I. Population-based trends in referral of the elderly to a comprehensive palliative care programme. Palliative Medicine 2002;16(3):255-6.

32. Maida V. Factors that promote success in home palliative care: A study of a large suburban palliative care practice. Journal of Palliative Care 2002;18(4):282-286.

33. Grande GE, Farquhar, M.C., Barclay, S.I.G., \& Todd, C.J. Caregiver bereavement outcome: Relationship with hospice at home, satisfaction with care and home death. Journal of Palliative Care 2004;20(2):69-77.

34. Parkes CM. Terminal care: Home, hospital, or hospice? The Lancet 1985;i:155-157.

35. Higginson IJ, Hearn J. A multicenter evaluation of cancer pain control by palliative care teams. Journal of Pain and Symptom Management 1997;14(1):29-35. 
36. Jones RVH, Hansford J, Fiske J. Death from cancer at home: the carers' perspective. British Medical Journal 1993;306:249-251.

37. Smeenk FWJM, van Haastregt JCM, de Witte LP, Crebolder HFJM. Effectiveness of home care programmes for patients with incurable cancer on their quality of life and time spent in hospital: a systematic review. British Medical Journal 1998;316:1939-1944.

38. Wilkes E. Dying now. The Lancet 1984;i:950-952.

39. Travis SS, Loving G, McClanahan L, Bernard M. Hospitalization patterns and palliation in the last year of life among residents in long-term care. Gerontologist 2001;41(2):15360.

40. Experton B, Ozminkowski RJ, Branch LG, Li Z. A comparison by payor/provider type of the cost of dying among frail older adults. Journal of the American Geriatrics Society 1996;44:1098-1107.

41. Pryer W. Query on life at any cost. The West Australian 200315 November 2003.

42. Burke K. Palliative care at home to get further funds if it saves money. British Medical Journal 2004;328:544.

43. Greer DS, Mor V, Morris JN, Sherwood S, Kidder D, Birnbaum H. An alternative in terminal care: Results of the national hospice study. Journal of Chronic Diseases 1986;39(1):9-26.

44. Chochinov HM, Kristjanson L. Dying to pay: The cost of end-of-life care. Journal of Palliative Care 1998;14(4):5-15.

45. Emanuel EJ. Cost savings at the end of life: What do the data show? Journal of the American Medical Association 1996;275:1907-1914.

46. Hearn J, Higginson IJ. Do specialist palliative care teams improve outcomes for cancer patients? A systematic literature review. Palliative Medicine 1998;12(5):317-32.

47. Critchley P, Jadad AR, Taniguchi A, Woods A, Stevens R, Reyno L, et al. Are some palliative care delivery systems more effective and efficient than others? A systematic review of comparative studies. Journal of Palliative Care 1999;15(4):40-47.

48. Salisbury C, Bosanquet N, Wilkinson EK, Franks PJ, Kite S, Lorentzon M, et al. The impact of different models of specialist palliative care on patients' quality of life: a systematic literature review. Palliative Medicine 1999;13(1):3-17.

49. Campbell M, Ritzpatrick R, Haines A, Kinmonth AL, Sandercock P, Spiegelhalter D, et al. Framework for design and evaluation of complex interventions to improve health. British Medical Journal 2000;321:694-696.

50. Higginson IJ. Evidence based palliative care: There is some evidence--and there needs to be more. British Medical Journal 1999;319:462-463.

51. Denzin NK, Lincoln YS, editors. Handbook of Qualitative Research. 2nd ed. Thousand Oakes, Calif: Sage Publications, Inc, 2000.

52. International Statistical Classification of Diseases and Related Health Problems, 1989 Revision. Geneva: World Health Organization, 1992.

53. Holman CD, Bass AJ, Rouse IL, Hobbs MS. Population-based linkage of health records in Western Australia: development of a health services research linked database [comment]. Australian \& New Zealand Journal of Public Health 1999;23(5):453-9.

54. Brameld KJ, Thomas MA, Holman CD, Bass AJ, Rouse IL. Validation of linked administrative data on end-stage renal failure: application of record linkage to a 'clinical base population'. Australian \& New Zealand Journal of Public Health 1999;23(5):464-7. 
55. O'Brien T, Welsh J, Dunn FG. ABC of palliative care: Non-malignant conditions. British Medical Journal 1998;316:286-289.

56. Poppel DM, Cohen LM, Germain MJ. The renal palliative care initiative. Journal of Palliative Medicine 2003;6(2):321-326.

57. Abrahm JL, Hansen-Flaschen J. Hospice care for patients with advanced lung disease. Chest 2002;121(1):220-9.

58. Low JA, Pang WS, Chan DK, Chye R. A palliative care approach to end-stage neurodegenerative conditions. Annals of Academic Medicine, Singapore 2003;32(6):778-784.

59. Head B. Palliative care for persons with dementia. Home Healthcare Nurse 2003;21(1):5360.

60. Adam SJ. Palliative care for patients with a failure liver transplant. Intensive Critical Care Nursing 2000;16(6):396-402.

61. MacMahon TS. Parkinson's disease, palliative care and older people: Part 1. Nursing Older People 2004;16(1):22-26.

62. MacMahon TS. Parkinson's disease, palliative care and older people: Part 2. Nursing Older People 2004;16(2):22-26.

63. Oliver D, Webb S. The involvement of specialist palliative care in the care of people with motor neurone disease. Palliative Medicine 2000;14(5):427-428.

64. Kutzen HS. Integration of palliative care into primary care for human immunodeficiency virus-infected patients. American Journal of the Medical Sciences 2004;328(1):37-47.

65. Moskowitz CB, Marder K. Palliative care for people with late-stage Huntington's disease. Neurological Clinics 2001;19(4):849-865.

66. Australian Institute of Health and Welfare (AIHW). Admitted Patient Palliative Care in Australia, 1999-00. Canberra: AIHW, 2003.

67. Little Company of Mary Health Care. A Snapshot of Palliative Care in Australia: Summary of the National Palliative Care Plan Initiative. Canberra: Commonwealth Department of Health and Ageing, 2003.

68. Jones L, Atkins A. Hospice Care Service Review. Silver Chain's Hospice Care Service Towards a Better Understanding of Client Service Needs. Perth: Silver Chain, 2003.

69. Glare PA, Virik K. Can we do better in end-of-life care? The mixed management model and palliative care. Medical Journal of Australia 2001;175(10):534-536.

70. Hoyert DL. Mortality trends for Alzheimer's disease: 1979-1991. Vital Health Statistics 1996;28:1-23.

71. Mannino DM, Brown C, Giovino GA. Obstructive lung disease deaths in the United States from 1979 through 1993. An analysis using multiple-cause mortality data. American Journal of Respiratory \& Critical Care Medicine 1997;156(3 Pt 1):814-8.

72. Camilli AE, Robbins DR, Lebowitz MD. Death certificate reporting of confirmed airways obstructive disease. American Journal of Epidemiology 1991;133(795-800). 